\title{
Becoming and being an opera singer: \\ Health, personality, and skills
}

Maria Sandgren

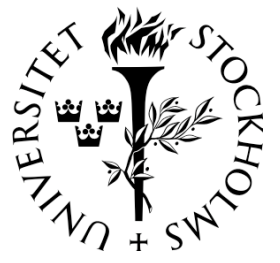

Department of Psychology

Stockholm University

Stockholm, Sweden, 2005 
(C) Maria Sandgren

Cover: Louis Jean Desprez "The garden of de la Gardie" from the opera "Queen Christina"

Printed with permission from The National Museum of Fine Arts, Stockholm ISBN 91-7155-039-9

Intellecta DocuSys AB, Stockholm 2005 
Doctoral dissertation, 2005

Department of Psychology

Stockholm University

SE-106 91 Stockholm

\section{Abstract}

The present thesis explores factors and processes associated with the artistic profession and development of opera singers. The profession of opera singers has a long story deriving its origin in early 1600s in Italy. What is performed on opera stages today is written in the musical scores in the $18^{\text {th }}$ and 19th century. The question arises how the modern opera singers live, learn and excel in their contemporary pursuit in order to meet the high demands on performance. The initial study identified health issues related to the professional activity of opera singers. Qualitative and quantitative measurements indicated that psychological problems were associated with a distinct worry for possible negative evaluation from significant others and a fear of vocal indisposition. A range of healthpromoting activities was demonstrated aiming at preventing the occurrence of somatic problems that could cause vocal indisposition. Psychosocial problems concerned difficulties to maintain a family life and relations due to irregular working hours. In Study II, the psychological and physiological effects of singing lessons were investigated with respect to amateur and professional levels of singing experiences. Amateur singers experienced more well-being measured by self-reports of emotional states and by lower levels of stress hormones than professionals. In Study III, narrative accounts were collected to identify factors and processes in the artistic development during higher opera education. A descriptive model was created that embraced the development of various skills such as singing technique, means of expressiveness and interpersonal skills. Outcome variables from the education were artistic autonomy, artistic competence and change in self-concept. In Study IV, personality characteristics were assessed among elite students in opera and business education representing an artistic versus a traditional educational streaming. Female opera students, female business and male business students shared the personality characteristic of extraversion indicating a disposition towards sensation seeking. Male opera singers exhibited a profile of elevated levels of emotionality. In general, the findings across the studies demonstrate that the individual development of operatic artistry is a complex process where health-related issues, personality characteristics, skills acquisition and sociocultural values are critical constituents. A major result was the marked focus on the instrument per se, the voice. Vocal functioning in singing was described as a means of enabling operatic singing, a mode for artistic expression and indicator of health.

Key words: Artistic development, opera singers, health, vocal ability, personality, skill acquisition, higher education. 


\section{Acknowledgements}

During the preparation of this thesis several persons have contributed to the progress. I am particularly indebted to my supervisor professor Henry Montgomery for his invaluable guidance and inspiration. Henry has a way of transmitting a particular attitude, that is how to keep up a fresh and open intellectual mind. In our discussions, what was static and rigid in scientific work became creative and dynamic, and what was intricate shone soon with clarity in its complexity.

I am also deeply obliged to my associate supervisor professor Britt af Klinteberg who was the one who initially introduced me to the doctoral work at the Department of Psychology, Stockholm. She showed me also the field of research on personality from a psychobiological view. As myself a so-called psychosomatician, I appreciate this knowledge very much. I have been privileged to have had two supervisors, Henry Montgomery and Britt af Klinteberg. Although they work in different scientific fields, it turned out to be a good mix and to broaden my thinking.

Professor Alf Gabrielsson was however my supervisor in the first part of the research work at the Department of Psychology in Uppsala. I am very grateful for his stimulating support and open mind in methodological questions. Somehow, I experienced artistic freedom in scientific work. This experience has given me confidence in conducting scientific work.

I would also like to express my appreciation to professor Töres Theorell and the nurse Tina Grape who invited me to be involved in a study about singing lessons.

All participants in the studies are greatly acknowledged for their contribution. Most of them are public persons, and yet they accepted to share their experience from artistic work.

The thesis was supported financially by The Bank of Sweden Tercentary through a grant to professor Alf Gabrielsson. I am also very grateful for financial support from Operahögskolan in Stockholm in an important phase of the doctoral work and also support from the Department of Psychology in Stockholm. 
At the department, I wish to thank my doctoral group Anna-Lena Erixon, Birgitta Falk, Münevver Malgir, Hanna Stillström and Gustav Törngren for being around. My gratitude is also expressed to colleagues and doctoral fellows for chats and serious discussions (none mentioned, none forgotten). And no doctoral work would be done without the key persons giving computer, administrative and technical support when needed, often urgently. Thank you!

Thanks to Stefan for the idea of how to visually illustrate the thesis. The result can be seen on the cover.

My sister Petra turned up and chose to settle down on the same geographical spot as I. This added some extra spice (with long-term effect) to the final phase of writing the thesis.

My doctoral work was the focus for my work life for some years. Additional professional experiences outside the academia offered divertissement and kept me in a good mood. I particularly think of collaborations in musical areas, in group relations, and also my work as a clinical psychologist. The musical world let me join them on the inside, and I had the opportunity to confront my research results with real life. The participation in group relations pinpointed structure, the complexities of social life and also play in order to orchestrate work. The human being is indeed the organizing principle of life. A similar experience comes from my clinical work that also constantly reminds me how critical relations are for health, learning, and development, but rather difficult to exactly measure in research. The overall conclusion is that theory and practice do meet, and sometimes not at all.

April, Stockholm 2005

Maria Sandgren 
Thank you for the music the songs I'm singing

Thanks for all the joy they're bringing Who can live without it

I ask in all honesty What would life be without a song or a dance what are we

"Thank you for the music" by $A B B A$ 


\section{List of studies}

The thesis is based on the following four studies, referred to in the text by their Roman numerals.

I. Sandgren, M. (2002). Voice, soma and psyche: A qualitative and quantitative study of opera singers. Medical Problems of Performing Artists, March, 11-21.

II. Grape, C., Sandgren, M., Hansson, L-O., Ericson, M., \& Theorell, T. (2003). Does singing promote well-being? An empirical study of professional and amateur singers during a singing lesson. Integrative Physiological \& Behavioral Science, 38, 65-74.

III. Sandgren, M. (2004). Learning experiences and motivation in artistic development. Manuscript submitted for publication.

IV. Sandgren, M. (2004). Personality characteristics among elite students in opera and business education. Manuscript submitted for publication.

Studies I and II have been reprinted with permission from the copyright owners Science \& Medicine, Inc. and Transaction Publishers respectively. 


\section{Contents}

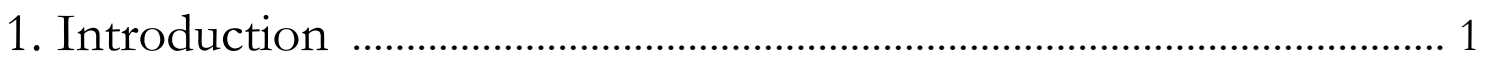

Overview of the thesis ......................................................................... 2

2. Historical background of opera tradition ............................................... 4

The origins of opera …………………..................................................... 4

The Swedish opera tradition and education …………………………......... 14

3. Transitional factors and processes in musical development .......... 17

Perspectives on giftedness and skills ......................................................... 17

Features of musical development ............................................................... 20

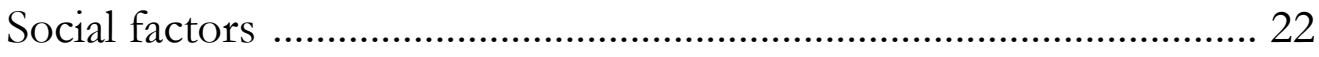

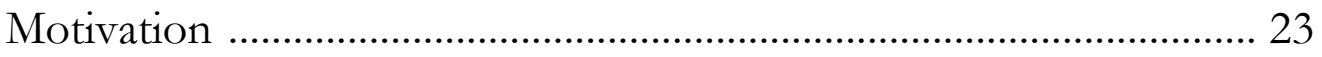

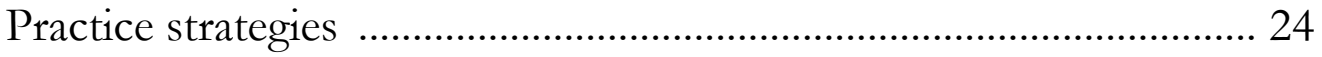

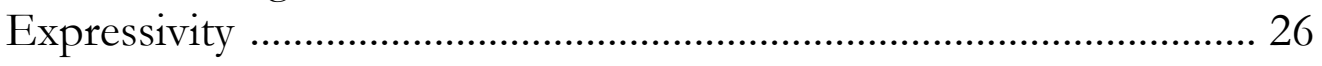

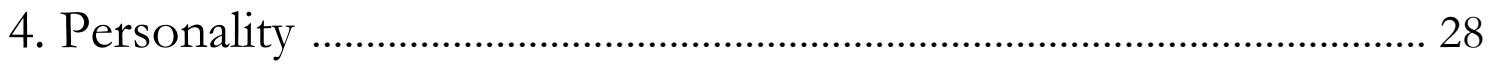

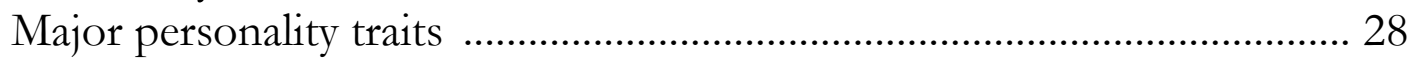

Personality and athletic activities ............................................................... 31

Personality and creativity ................................................................................ 33

Personality and vocational interests ............................................................ 34

5. The performing professional and health issues .................................. 37

Aspects of vocal production ……………………….................................... 37

A psychological view of artists and health .................................................. 39

A medical view of the professional singing voice ......................................... 42

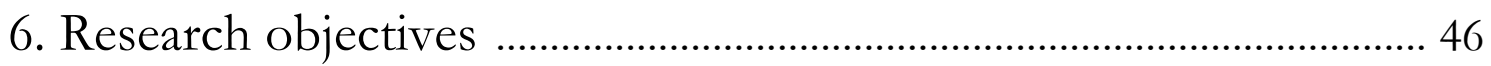

7. Methods and materials .............................................................................. 47

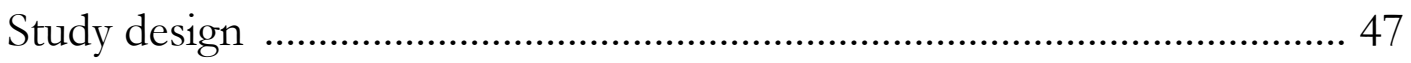

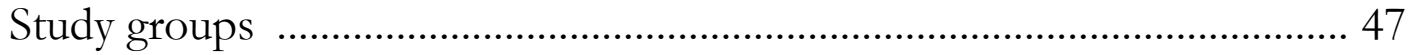

Inclusion procedure ............................................................................. 50

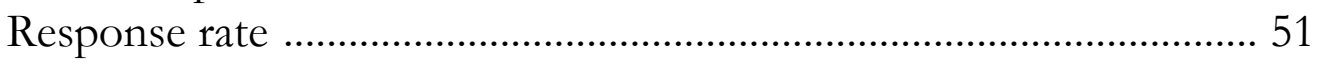

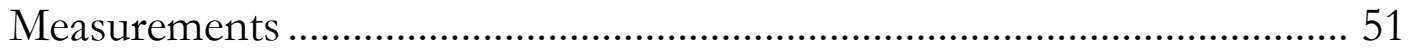

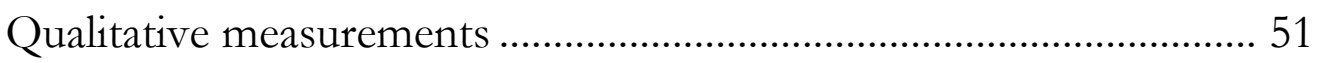

Quantitative measurements ................................................................. 53

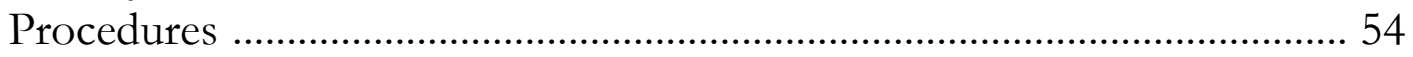

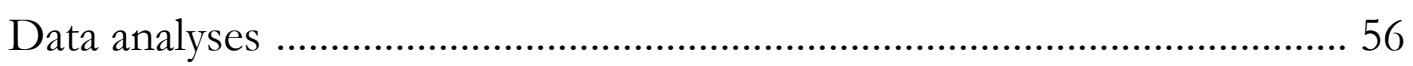

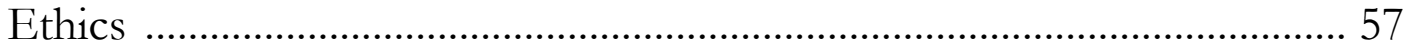


8. Overview of empirical studies

Study I: Voice, soma, and psyche

- A qualitative and quantitative study of opera singers 58

Study II: Does singing promote well-being? An empirical study of professional and amateur singers during a singing lesson ........ 60

Study III: Learning experiences and motivation in artistic development.. 61

Study IV: Personality characteristics among elite students in opera and business education

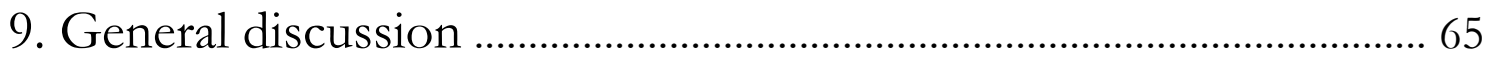

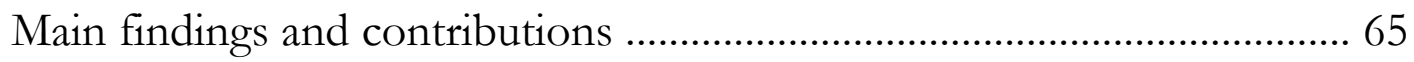

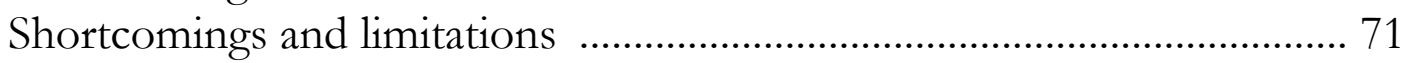

Concluding remarks and future directions .................................................. 73

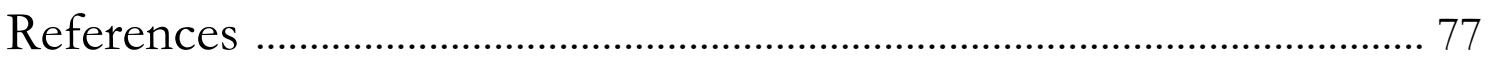

Original studies (I-IV) 



\section{INTRODUCTION}

The present thesis investigates factors and processes associated with the artistic profession and development of opera singers. More specifically, health issues, personality characteristics and skill acquisition were examined.

As a point of departure, it should be reminded that the profession of opera singers has a long story. Opera developed early in 1600s in Italy, animated by the Renaissance spirit. This new art form combined words, music and drama, a style that basically remains the same even today. Today's major opera works performed on stages around the world originate from the $18^{\text {th }}$ and $19^{\text {th }}$ century. An opera singer's highly sophisticated vocal performance is still essential to the operatic performance. Opera singers are challenged to fulfil the artistic values written in the musical scores and at the same time excel in their individual expression.

The question arises how the modern opera singers face the high demands on artistic skills and professional expertise. In addition to the demands they place on themselves and the demands their colleagues place on them, an audience can immediately compare their performance with numerous recordings. Like professional athletes, opera singers have conditioned themselves to perform consistently at a high level. Both professional athletes and professional opera singers use their body as a means for high achievement. However, there is one major difference. The career of athletes is much shorter than the career of opera singers. Comparisons between opera singers and instrumentalists such as violinists and pianists in the classical genre are also valid, as professional musicians and opera singers both rely on continual training to develop and maintain their skills. Yet the instrumentalists have an external instrument to play on. To be able to perform on a high level is the outcome of years of training and of a particular aptitude for a particular artistic expression. Despite similar work conditions with other high achieving professions, psychological research has not investigated opera singers and their pursuit. Although 
opera singers are part of a long and strong tradition, very little is known about how they live, learn, work and excel in their contemporary pursuit.

This thesis is an attempt to elucidate certain factors and processes in the artistic profession and development of opera singers from a psychological point of view. As research is lacking, an exploratory approach is applied using both qualitative and quantitative methods. The particular experiences of opera singers are in focus. Questions raised in the present thesis are related to the use of an opera singer's instrument - the voice. The voice can be regarded as a means of artistry as well as indicators of health. From the view of individual differences, certain personality characteristics for artistic achievement are expected. Other issues for investigation regard the formative process in higher opera education. The demands on musical skills are set in the musical scores, but the learning process might involve additional features necessary for artistic development.

\section{Overview of the thesis}

The aim of the thesis introduction if fourfold, (a) to place the contemporary profession of opera singers in a historical perspective, (b) to illuminate certain key features and processes in opera singers' artistic development, (c) to describe a theoretical basis underlying the empirical studies, (d) to further develop theoretical themes suggested in the studies. The introduction comprises nine sections, and four empirical studies are included in the thesis. In the following section, a historical background is presented of the profession as opera singers. This section situates the contemporary opera singer in a historical perspective by giving an overview of the development of the individual singing expression, of changes in operatic modes, and of examples of performance and educational settings. This section constitutes a general outline for the current thesis and as the background for Study III. In the third section, transitional factors and processes in musical development are addressed. Theoretical perspectives on talent versus skill acquisition account are presented. Salient factors and phases in musical development are defined in a general overview. This section provides an additional framework for Study I, II and III. Section four elaborates the underlying theoretical 
assumptions regarding trait theory and focuses on personality traits as constituents for high achievement and choice of profession. This section forms the background for Study IV. The fifth section addresses health issues in relation to the performing profession. The focus is on psychological and medical factors relevant to performance and specifically to the professional singing activity. A short description of vocal production is given. This section aims at providing a point of reference for Study I and II. Following this, the sixth section presents the research objectives for the current thesis, and the seventh section describes methods and materials used in the empirical studies. In the eighth section, the four empirical studies are examined together with some comments on the results. The ninth section discusses major findings and contributions of the current thesis. Shortcomings and limitations are elaborated, as well as future directions for research discussed. 


\section{HISTORICAL BACKGROUND OF OPERA TRADITION}

This section provides an historical overview of opera tradition and education to situate the present thesis in a long line of operatic life, yet with a focus on psychological aspects. Opera history deals generally with musical notation scores, composers and to a modest degree sociology. Opera emerged as a new art form in the midst of the last millennium and has basically remained the same to this date. This sketch of the development of the opera genre shows that the circumstances surrounding opera dictated the form and vice versa. In addition, this section highlights social contexts and the development of artistic individualism, and vocal expression are highlighted.

\section{The origins of opera}

To decide upon a date that represents the birth of opera is a matter of perspective. In 1637, the first commercial opera house Teatro San Cassiano in Venice opened. In London, two years later a second public opera house was inaugurated. This was the beginning of a sophisticated entertainment industry. This fact does in no way suffice to understand the creation of this new art form of opera blending elaborated elements of music, drama, words and song. Early opera dating from around 1600 was and still is a form of Gesamtkunstwerk ${ }^{1}$. A further attempt to follow the genesis of opera would place us in the Middle Ages when the central dramatic forms were religious. The church was the dominating institution for music. Liturgical plays and church rituals were common and included the elements such as drama, costumes, song and music to convey the religious message to illiterate

\footnotetext{
${ }^{1}$ Wagner, in 1849, coined the term of Gesamtkunstwerk (German vocabulary) which he found to be the ideal for musical drama. A Gesamtkunstwerk can be defined as the ideal way for integrating different artistic modes (poetry, music, acting, painting etc.) to a higher aesthetic synthesis (Sohlmans musiklexikon, 1975).
} 
citizens. The language was mainly Latin. Musicians were considered craftsman. Musical activities were a main duty for the churchmen and honoured them with ecclesiastical status. The singing was represented by choir, and solo performances were rare at this time (Martorella, 1982; Orrey, 1987; Sadie, 1989). By the $13^{\text {th }}-14^{\text {th }}$ centuries, the liturgical plays were elaborated into the Mystery Plays that also were performed in churches. When the plays changed location to outside the church, the plays involved secular pageants and entertainment. The plays could be found all around Europe at this time, and the Italian versions were known as Sacre Rappresentazioni. The music was arranged for one or more voices and sung in Italian throughout in recitativo ${ }^{2}$. It is claimed that Sacre Rappresentazioni significantly influenced the development of opera in the $16^{\text {th }}$ century, but no written musical scores have survived (Orrey, 1987).

By the end of the Middle Ages, precursors to opera can be found in musical dramas connected with courtly entertainment in Italy. The aristocracy used grand spectacles with dramatic elements to celebrate births and weddings. The search for spectacular visual and vocal displays contributed largely to the conception of early opera. A particular antecedent was the intermedi or interludes, episodes or tableaux performed with music and often with mobile machines between the acts of plays. However, music was not considered to be a central factor in the setting of the entertainment. Aside from these occasional pieces of courtly entertainment, musico-drama activity began to spread in groups of intellectuals who played a considerable role in the advancement of learning during the Renaissance. There were many literary and artistic societies. In the cities of northern Italy, the geographic area of greatest importance of the up-coming genre opera, the aristocrats reflected the ideals of the Renaissance. In 1425, the patrons of the Gonzaga family invited Vittorino de Feltre who created a centre Mantua of learning and the arts in Mantua. Painters, musicians and composers of madrigals excelled in their arts under the benevolence of the Gonzagas. Still, there was no emphasis on virtuoso technique or individual expression (Orrey, 1987; Sadie, 1989). Yet, the intellectual atmosphere of the Renaissance was favourable to

${ }^{2}$ Recitativo comes from Latin, recitare, to tell. A form of singing that imitates natural rhythm and modulation of speech. The function of recitativo in opera is to express the content of a dramatic text (Sohlmans musiklexikon, 1975). 
individuality and the development of professionalism in art. The individual who was engaged in artistic activity attained high status. To educate their offspring in music became of great concern for aristocratic families. During this time, generations of music lovers were produced. Although music was taken seriously, the notion of the skilled musician was not yet established and amateurism flourished (Martorella, 1982).

Around 1570 through 1592, the Florentine Camerata - a society of musicians, poets, philosophers and scholarly members of the nobility gathered near Florence at the house of Count Bardi, a wealthy patron. The Camerata included composers such as Rinuccini, Peri, Caccini and Galilei. They sought to reproduce the music of the Greek drama in the way they believed it had existed in terms of song, chorus, declamation/chant and dance. The ideal of monody ${ }^{3}$ was revived where harmony, melody and rhythms would allow the dance and song to excel. Music should not only offer pleasure, but it should edify and exalt the soul of the human being. The Camerata created the notion of stilo recitativo, a kind of single vocal line sung in a declamatory style with musical accompaniment. The idea was to express the meaning of the words and drama more intensely. It was argued that recitativo was superior to spoken verse, since the musical elements intensified the implied emotions. Another forerunner to opera was the pastoral drama, a combination of poetry and song comprised by musicians and poets. Pastoral plays included generally song, chorus and dance, often offering happy endings (liteo fine). The genre gave expression to the characters and scenes of rural life. The earliest known pastoral play is Orfeo by Poliziano (around 1480) and was performed at a festival at the court of Mantua (Davies, 1981; Donington, 1981; Kimbell, 1991; Lindenberger, 1984; Littlejohn, 1992; Rosselli, 2000; Sadie, 1989).

Opera is believed to have taken its more contemporary form by 1600 in Florence, Italy. The first work of opera is regarded to be Dafne by Peri and performed the first time in 1598. Other operatic works

\footnotetext{
${ }^{3}$ Monody is an ambiguous term. In this particular period of the $17^{\text {th }}$ century Italy, the term denotes solo vocal music of secular kind and is associated with the attempt to revive ancient Greek musical ideals. Monody is a contrast to polyphonic profane music (where all vocal parts have equal significance and value to the musical form) occurring in Middle Age Europe (Sohlmans musiklexikon, 1975).
} 
relied also considerably for the drama plot on the classical Greek myth of Orpheus and Eurydice such as Euridice by Peri in 1600 and by Caccini in 1602 with the libretto by Rinuccini's poem, and also Orfeo by Monteverdi in 1607 (Grout, 1965; Orrey, 1987). The compositions by Peri and Caccini lacked musical organization and characterization, emotions were poorly expressed, and the solo parts were monotone in style. Monteverdi, on the other hand, expanded the possibilities of the operatic performance (Grout, 1965).

Monteverdi (1567-1643) respected the primacy of drama in opera, developing a new type of musical expression. He believed that emotions such as anger or excitement had not found expression in the music, and consequently new devices of instrumental technique had to be created, a belief that required him to change the way voice was used. This new type of musical drama required that the singers were able to express a whole range of feelings. The mythological plots focused on the human being and human pleasures, sufferings, passions and deeds. The 'dignity and excellence of man' was the major theme, and the human being and his reality continued to be the central plot of Italian opera through today (Grout, 1965; Kimbell, 1991; Lindenberger, 1984; Orrey, 1987).

Around 1600, the various modes of expression such as dancing, playing an instrument, singing and composing were not seen as distinct specialities. Singers were mentioned as 'acting in song' (recitar cantando). In addition, they were called actors or musicians in an opera. These singers often came from the church. Most of them were castrati. Boys were castrated and trained for professional careers in church choirs, as the music was written for higher-pitched voices and women were forbidden to perform in church. Moreover, Italian opera required a hero or lover. The castrati were the 'primo uomo', the main male figures on stage. Around 1700, the castrati were the most important performers, only rarely matched by the prima donna, the female singer. These opera plots included often female characters disguised as men or vice versa. The higher-pitched, anti-realistic and stylized voice of castrati added to this sexual ambiguity of the central characters. After 1740 in Italy, castration was no more accepted for musical ends (Rosselli, 2000).

In the last decades of the $16^{\text {th }}$ century, the development of instrumental virtuosity was initiated. Consequently, the importance of 
musical skill and ability was enhanced. In the beginning of $17^{\text {th }}$ century, musicians and singers started to support and encourage each other's individual contribution to the musical expression, although vocal performance was rated superior to the instrumental contribution (Celletti, 1991).

In Italy, the genesis of music conservatories is to be found in charitable institutions in the $17^{\text {th }}$ century. Professional musical training was part of the education in Italian ospedali for orphans and underprivileged children. Because musical training was expensive, the only other trained musicians were the privileged elite. In these forerunners to music conservatories, orphaned and illegitimate girls were given training in vocal, choral and instrumental music. These institutions were called ospedali as they were originally attached to hospitals. The first known ospedali was in Venice. Similar institutions were also found in Naples and called conservatori (Mark \& Gray, 1992). Also castrati were raised and educated at the famous conservatories (Rosselli, 2000). The French philosopher Rousseau and the German writer Goethe wrote about the beauty of the public concerts at the ospedali. Great Italian composers, such as Monteverdi and Cavalli, offered tuition and composed music for the ospedali students. Eventually, other than underprivileged children could also receive musical training at the ospedali. The demand for skilled musicians increased because of the strong public interest for opera and other musical performances. Choir schools also offered musical training. Haydn (in the $18^{\text {th }}$ century) and Schubert (in the $19^{\text {th }}$ century) were both students at choir schools (Mark \& Gray, 1992).

Formal changes in the opera compositions occurred in the first half of the $17^{\text {th }}$ century: recitativo was separated from the aria ${ }^{4}$, and solo parts increased. Between 1715 and 1720, a kind of acrobatic vocalism became popular. Composers began to produce work that highlighted the human voice, placing higher demands on vocal skills. For example, the singer was expected to imitate wind beating the waves on rocks, as written in the complex musical scores in a 'tempest' aria in Amor di figlia (1718) by Porta. Simultaneously, the singers were required to sing

\footnotetext{
${ }^{4}$ Aria originates from Italian vocabulary and means air. Aria is the solo part for the singer often accompanied by orchestral instruments in operas, oratorios, and cantatas. These solo parts were the major expressive vehicle for the opera singer in the $17^{\text {th }}, 18^{\text {th }}$, and $19^{\text {th }}$ century (Sadie, 1992).
} 
- a kind of musical symbolism, a common mode among composers at that time. The waves' beating on the rocks was a symbol of the beating of the heart (Celletti, 1991). During this time, formal changes were being made for instrumental arrangements in the orchestra. The modern orchestra was established with the violin instruments in the centre of the orchestra (Lindenberger, 1984). Additionally, the social context for operatic performances changed. Opera gained a new and paying audience due to the rise of mercantilism. Opera left the aristocratic arena in favour of public theatres. The new middle class preferred comic elements and scenes from rural life and real life situations (Lindenberger, 1984; Martorella, 1982). This new musicodrama popularity was reflected in the increased number of opera theatres. This new musico-drama interest was reflected in the increase of number of theatres: 16 commercial theatres were built between 1637-1700 in Venice, and 400 productions were given by 1700 . Aristocratic families also launched themselves into the theatre business with little success (Lindenberger, 1984; Orrey, 1987; Sadie, 1989). In the theatres, the number of orchestral players was small and the cast included 6-8 singers, a chorus (of for example soldiers), and a small string group. This new audience preferred extravagant spectacles, such as cloud machines and magical effects (Orrey, 1987). By 1790, the instrumentalists in the orchestras grew in number to around 60: most of these were strings and woodwind players (Rosselli, 2000). In addition to operatic performances in theatres, itinerant troupes of singers and other performers circulated in Italy and offered public entertainment that borrowed elements from commedia dell'arte ${ }^{5}$, musical and dramatic features of operas (Lindenberger, 1984).

Opera began to be performed outside Italy in the $17^{\text {th }}-18^{\text {th }}$ centuries. Singers, composers and instrumentalists were exported from Italy to England, France, Spain and Russia. German composers also visited Italy for inspiration (Martorella, 1982). Two subgenres to opera emerged, serious opera (opera seria) and comic opera. Serious opera was a matter for all European courts, whereas comic opera played upon character drawing. In the latter genre, dialogue was not sung but spoken, because the details of the intrigue had to be distinctly

${ }^{5}$ Commedia dell'arte connotes a comic stage representation performed by touring troupes in Italy between 1550 and 1750. The performances involved semiimprovised plots with fixed parts, song, dance and masks (Sadie, 1992). 
transmitted, which induced further development of the musical form. Moreover, the development of operatic expression was in the hand of the composers (Grout, 1965; Orrey, 1987). In France, Lully, Rameau and Gluck dominated the operatic scene in the $17^{\text {th }}$ and $18^{\text {th }}$ century. The French style emphasised plot, lavish visual presentations, and simple musical forms. The literary form was expanded by Metastasio, a court poet in Vienna. His libretti were used in operas by for example Mozart, Handel, Hasse and Gluck. In the $19^{\text {th }}$ century, Wagner envisioned opera as a total fusion of art forms, the Gesamtkunstwerk. In England, opera remained primarily a national development compared to other European countries, although Handel and Haydn produced opera works with Italian influence for British audiences. In Italy in the $18^{\text {th }}$ century, Scarlatti, Pergolesi, and Jommeli were other examples of important composers.

Looking back in opera history, it will show that changes and development in the genre have taken place, although some values of operatic expression and the social context have prevailed. The signification of the singer and the aria has to a large extent subsisted, as well as the exclusive cultural surroundings of opera performances up to date. In the $18^{\text {th }}$ century, the audience was mainly interested in the vocal performance of the major roles, usually by the castrati and the prima donnas, performers who led luxurious lives, beloved by courts around Europe. The arias and consequently the singers assumed dominant positions, allowing them to experiment with improvisation. By experimenting with their vocal skills, the singers prepared for the foundation for bel canto ${ }^{6}$. Composers wrote musical scores to suit the virtuosity and sometimes also limitations of popular singers, both castrati and prima donnas. An opera was regarded as a succession of arias where the other parts - ensembles, instrumental numbers and recitatives - were relegated to supporting role status. Between 1820 and 1835, Italian prima donnas rose in popularity, providing them with the cachet to express their artistic freedom. The

${ }^{6}$ Bel canto is an indistinct term signifying an elegant Italian vocal style of the $18^{\text {th }}$ century (Italian vocabulary for 'fine singing'). The term appeared when bel canto singing was on decline and was used in a nostalgic sense in the $19^{\text {th }}$ century. The style of bel canto implies that the singer emphasises a sophisticated vocal technique more than dramatic expression in his or her performance (Celletti, 1991; Sadie, 1992). 
Italian style of opera dominated the opera houses in Europe, with the exception of France, and was performed in the Italian language. The dynamic music life in private colleges, convents, aristocratic salons and opera houses became a sign of prosperity and strength of towns and countries (Grout, 1965; Martorella, 1982; Orrey, 1987; Sadie, 1989).

In the $19^{\text {th }}$ century, paramount Italian composers were Rossini, Bellini and Donizetti. In addition, the orchestra played a greater part in the performance, opera houses grew bigger, and the opera singers (and composers) adapted to the new circumstances by developing an extraordinary singing technique. Rossini's compositions reflected the ornaments and cadenzas, parts that vocalists previously had improvised. A pivotal composer was Verdi who dominated the Italian opera life from 1850 to 1900 . Verdi's characters inspired by real life rather than mythological figures, a source of inspiration associated with earlier composers. Moreover, he favoured the vocal expression of human passions such as greed, ambition, love and loyalty instead of emotional abstractions. Like some of his predecessors in bel canto, he relied on melodious and simple orchestration (Grout, 1965; Orrey, 1987).

Between 1880 and 1920, a second golden era of singing, the veristic style ${ }^{7}$, was popular. The operatic plots included more elements from drama of real people's life. The musical form had changed again, requiring the singer to make use of more dramatic cues rather than depending on vocal virtuosity, and interpretation of music and character. The arias were no longer closed numbers. The opera singer had assumed the position as interpreter in the opera society. The thorough-composed operas emphasised both melody and arias, yet the singer continued to be the centre of the opera plot (Martorella, 1982).

By the $20^{\text {th }}$ century, Wagner's influence was undeniable. However, Strauss developed the use of orchestration and wrote operas based on Greek mythology and literary works. In his last opera Capriccio (1942), he elaborated on the eternal debate between the primacy of text or music in opera. The Wozzeck (1925) by Berg is the most enduring of atonal operas. Stravinsky and Hindemith, two of many composers,

${ }^{7}$ Verismo (Italian vocabulary for realism) is a movement in the late $19^{\text {th }}$ century (Sadie, 1992, 1989). Verismo was initially a literary concept and was adopted by the opera form in using narratives of lower social class subjects, true-to-life approach and strong emotions like hatred, lust and betrayal. 
also broke away from Wagnerian ideal. The Italian influence of Verdi found a successor in Puccini. In Russia, a number of opera composers emerged such as Prokofiev. In England, Benjamin Britten is one of the most acknowledged composers after World War II. Avant-garde operas include works by Penderecki and Ligeti. In the second half of the $20^{\text {th }}$ century, several people from theatre have directed operas; Peter Brook, Peter Hall, Jonathan Miller, Peter Sellars (Orrey, 1987; Sadie, 1989). What is important to bear in mind is that music history is the history of composers (Cook, 2000). Traditionally, the focus has been on innovation rather than tradition, composers rather than performers. That is creation, not reproduction, receives the most attention.

The critic David Littlejohn (1992) summarizes eloquently the history of the central artist in opera as follows: in the days of early opera, it was the Age of the Poet beginning with Rinuccini and ending with Metastasio. The written word was considered superior to music. Thereafter, it was the Age(s) of the Singer. This period of time was characterized by the indispensability of highly gifted singers and lasted from the Baroque to primo ottocento ${ }^{8}$. Next came the Age of the Composer that embodied great composers like Rossini, Verdi, Wagner, Puccini and Strauss. They composed, conducted, and excelled in their authority over libretto, staging and singers. Then the conductor entered the scene as the major authority. The Age of the Conductor lasted the first half of the last century and can be exemplified by Toscanani and his interpretation of Traviata (by Verdi) and Furtwängler of Tristan (by Wagner). Finally, in the last half of the last century, the Age of the Producer was established. The producer organizes and hires staff, set designers, directors, and possible conductors. Staging of opera has gone through many significant transformations in addition to the more traditional performances also offered. Often standard works are re-interpreted. Sometimes the stagings are even labelled 'misconceptions'. However, it is unclear what aesthetic trends and financial power will influence opera production in future.

Today, it is evident that musical and artistic values in opera have largely sustained over time. Since the castrati disappeared from the scene, the dramatic soprano has been the single most compelling vocal

${ }^{8}$ Primo ottocento is Italian and designates the period of $1800-1850$. 
range in opera works. To note is also that the standard repertory in the opera houses around the world originates from the $18^{\text {th }}$ and $19^{\text {th }}$ Italian and German tradition (Littlejohn, 1992). The dependence on skilled singers has prevailed, as the aesthetic values for vocal performance are written in the musical scores. A list of the 100 works most frequently performed by professional opera companies and festivals internationally in 1988-1989 shows that 1 opera work was composed in the $17^{\text {th }}$ century (by Monteverdi), and 9 operas were composed in the $18^{\text {th }}$ century (most of them by Mozart). Furthermore, 58 operas from $19^{\text {th }}$ century dominated the list of which were 31 from Italy, 14 of German-Austrian origin (the majority by Wagner), and 8 from France. The majority of the 22 operas from $20^{\text {th }}$ century are found among the less seldom performed works (4 from Italy, 7 of GermanAustrian origin, 5 from Great Britain, only 2 from France). It should be noted that the list covers only major opera stages, and not vocal performances in concert halls or churches.

Indeed, opera has a long history, and the discussion about the value of classical music in the contemporary society prevails. Nicholas Cook (2000), a musicologist, concludes that the classical tradition has become static due to demands on pure music and authenticity. Classical musicians have often the ambition to play or reproduce the music as it was originally played and according to the original notation. It is impossible, however, to know how musicians and directors interpreted the original scores. There exists no original version in that sense, only in the way of thinking about music. In addition, the classical music that we hear consists mainly of traditional works by major composers. In the opera world, few new works are added to the repertoire. Moreover, the way of blending genres is rarely accepted in traditional concert halls, but crossing the boundaries the other way around may prove itself to be a big niche with economic power: For example, the "Three Tenors" - Domingo, Pavarotti and Carreras - left the traditional operatic scene to perform opera arias for a new audience worldwide at a football world championship. Furthermore, subsidized and extravagant opera houses and concert halls might appear offensive to certain people. Another major transformation has influenced the public expectations. The technical development with sound reproduction has resulted in numerous recordings available to the public. Today, an audience may compare live performances with 
their recorded versions of the opera. Some believe that classical music and opera is on the decline or even 'dead'. This argument is difficult to maintain, as technology has provided, besides recordings, also means to easily access music. At no time in history, has so much music been so available to so many people.

\section{The Swedish opera tradition and education}

Very little is known about the history of Swedish opera tradition and education: this is apparent by the fact that no comprehensive literature exists in these areas. There is evidence that touring groups of actors and musicians from abroad visited Stockholm, starting with German groups as early as in 1721. The cultural life developed considerably during the reign of the King Gustav III (1746-1792). Gustav III was influenced by the cultural life abroad, particularly from France, and combined his strong cultural interest with political ambitions. In less than 15 years, the standard of Swedish opera productions approached the standard of other European countries' opera productions. The Gustavian opera was an endeavour with strong foreign influences. Even if the libretti were written in Swedish and the character development and plots included national subjects, the stories were of foreign origin. French set designers, choreographers and ballet-masters as well as German and Italian composers were hired. Interestingly, Gustav III preferred the genre serious (grand) opera, whereas the dominating trend in other parts of Europe was comic opera. In 1773, the Royal Theatre was inaugurated with a performance of a Swedish opera, Thetis and Pelée, set to music by Uttini and to words by Gustav III. Gustav III was the greatest dramatist during this period. In addition to the creation of opera productions, theatre and opera houses were built. In 1786, Gustav III founded the Swedish Academy inspired by the creation of the French Academy, although the initiative to establish a Music Academy was of an earlier date and by private citizens with strong interest in music as well as by professional musicians. In 1771, the Music Academy received royal sanction (Royal Swedish Academy of Music, 1991; Skuncke \& Ivarsdotter, 1998). The Music Academy's aim was to be a scientific institution and to provide musical education within the fields of composition, vocal music and instrumental music. In 1786, another initiative to educate singers and 
musicians came from the Royal Theatre. The Music Academy had grand visions for its activities that widely exceeded financial resources. Inspired by the Paris Conservatoire National de Musique ${ }^{9}$, Prince Carl Johan provided financial support in 1814. The activities expanded with the aim to educate professional musicians (mainly instrumentalists) in Stockholm, to provide education for director musices (music teachers) and musicians working in schools and churches. King Oscar, however, provided the vision and support for Sweden's first music conservatory. In the $19^{\text {th }}$ century through the early part of the $20^{\text {th }}$ century, theatres and opera houses educated opera singers (Luterkort, 1998; Morales \& Norlind, 1921). Thereafter, literature is unfortunately lacking regarding singing and opera education. In the 1960's, formal opera education was provided at a public university college of drama in Gothenburg (Anders Wiklund, personal communication, February 21, 2005), and at an independent public university college was founded in Stockholm (Operahögskolan, 2005).

Considering the Swedish opera history in the $19^{\text {th }}$ century, the genre of lighter opera works, vaudeville and significant international works were well received by the audience. Composers of classical music, such as Lindblad and Berwald, made efforts as well in music drama. Some Swedish musicians and composers were educated in Germany and had their works performed abroad such as Hallén. Nationalistic themes are evident in operas by Hallström and two music dramas by Stenhammar. In the first part of $20^{\text {th }}$ century, romanticism was the major trend. Composers of this genre were Peterson-Berger, Rangström and Atterberg. An example of the later movement of modernism was works of Rosenberg. Later, neo-classical ideas were formed by Frumerie, Bäck, Blomdahl and Werle (Sadie, 1989).

Swedish singers are known in the international opera history. In the $19^{\text {th }}$ century, Jenny Lind, a soprano, became an international star and performed in Europe and U.S.A.. She stopped singing already at the age of 29 (Franzén, 1982). At the end of the $19^{\text {th }}$ century, Christina Nilsson, another soprano, also performed successfully on stages in Europe and U.S.A.. A qualitatively different soprano was Birgit Nilsson who established herself as the major Wagner soprano in the

\footnotetext{
${ }^{9}$ In other parts of Europe, only the Paris Conservatoire National de Musique has its origin around this time, namely in 1784 (Mark \& Gray, 1992).
} 
$20^{\text {th }}$ century. One of the most internationally recognized tenors was Jussi Björling. Both Birgit Nilsson and Jussi Björling were students the Music Academy in Stockholm. Jenny Lind was a student at the age of 9 at the Royal Opera in Stockholm (Sohlmans musiklexikon, 1975; Sørensen, 1993). 


\section{TRANSITIONAL FACTORS AND PROCESSES IN MUSICAL DEVELOPMENT}

This section embarks on an introductory outline on perspectives of giftedness and skills. The second part of the section highlights previous findings on factors as well as phases in musical development. Research on musical processes covers many areas - cognition, motivation, and perception among others, although there is a paucity of theoretical discussions. Additionally, the extant research has focused on the development and performance of the student: few studies have addressed the adult or professional artist. The few studies that address classical singers are also included in this section.

\section{Perspectives on giftedness and skills}

Generally, researchers agree that giftedness or talent is not only the expression of a personal disposition, but also the fulfilment of a cultural potential (cf. Sternberg \& Davidson, 1986). Categories of giftedness can be described to discriminate between the kinds of acknowledgement and admiration they evoke in society. Musicians and opera singers are representative of surplus talents according to this view (Tannenbaum, 1986). Individuals involved in the production of art, music and literature have an unusual ability to stimulate people's sensibilities. It is suggested that the need for these talents demonstrates a craving for enhancing life quality (self-serving) in the society rather than a demand for preserving life (self-preserving) as represented of scarcity talents (in medicine, psychiatry, and politics). Secondly, Tannenbaum suggests that giftedness manifests itself in classifications of ability. Performing artists would then exemplify those who perform skilfully and consistently well in front of an audience or similar contexts. Another classification represents skills in producing important new creative ideas or material inventions. Therefore, if talent depends on social attributions rather than on a trait based in the child's biology, then talent should be conceived not as a stable trait but 
as a dynamic quality dependent on changes within the individual and the environment.

In order to shed light on the various concepts of giftedness and talent (cf. Horowitz \& O'Brien, 1985), giftedness is commonly ascribed to the child who shows early evidence of gifts (precocity), an unexpected manifestation. The gifted or talented child might show a great potential for becoming a pianist, but the gift or ability does not depend on any greater effort. Creativity has another meaning. Creative work is generally ascribed to the works of the adult after sustained efforts: that is, the adult has developed his or her initial talent and is able to produce original works.

Traditionally, the construct of musical ability has been related to sensory capacities, more particularly auditory elements such as pitch, rhythm and tonality (cf. Shuter-Dyson, 1999). From this perspective, individuals achieving extraordinary well in music-making would do so due to innate talent compared to less well achieving individuals, a view of talent that agrees with folk psychology (Winner, 2000). Today, the views on musical abilities are multi-fold and include various factors (personality, cognition, psychosocial factors, learning and performance skills), and interrelated processes between factors (see Hallam, 2002). Hallam (2002) found that the term musical ability was differentially conceptualized in the groups of adults and children as well as among musically skilled and non-skilled individuals.

As a proponent for the biological base of abilities, Gardner (1983) states the existence of multiple intelligences, each resulting in one of seven relatively independent basic talents. Agreeing with a personenvironment approach, Gardner proposes that the development of talents depends on the specific psychobiological organization that makes the child more sensitive to a particular range of stimuli and better able to function within it at a superior level, relating musical intelligence to a particular sensitivity to pitch, rhythm, and timbre, all of these being aspects of the auditory sense. Another feature might be an affective component, a kind of ability to capture and form feelings in terms of musical expression. Singing and music might be regarded as modes for emotional expressions from a singer's or musician's point of view (see Juslin \& Laukka, 2003 for review). Investigations have aimed at decoding emotions from acoustic cues such as pitch, temporal aspects, intensity and timbre. Some consistent findings were 
presented. In both musical and vocal (speech) expression, the use of high pitch was related to happiness and anger, and the use of low pitch to sadness and tenderness.

The nature-nurture controversy considering musical innate ability was debated in a target article with open-peer commentaries (Howe, Davidson, \& Sloboda, 1998). This article presented evidence that supported and challenged assumptions of innate talent with respect to exceptional accomplishments. The authors concluded that the "difference in early experiences, preferences, opportunities, habits, training, and practice are the real determinants of excellence" (p. 399). The peer commentaries varied from full support for the view of Howe et al., taking the person-environment interaction into account ("fruitless polarities", p. 411), to complete dismissal, asserting that genetic factors play a vital role (p. 415). One reviewer noted that this approach addressed "policy issues" rather than scientific questions (p. 431).

In respect to the foregoing nature-nurture debate, attention should be drawn to common notions about the term 'innate' relating to human behaviour (Bateson, 1996). Bateson found that six separate meanings could be related to the term; the disposition should be present at birth; behavioural differences are caused by genetic differences; the disposition is an evidence of adaptation over the course of evolution; it does not change over the development; it is found among all members of a species; and it is not learned. The practical difficulties are apparent in merely solving the question if whether a behaviour is learned or innate. It remains, however, for the speaker to be aware of and articulate which meaning he or she attaches to the term of 'innate'. There have been attempts to identify early manifestations of 'natural' musical talent by interviewing parents of talented young musicians, but this view fails to provide much in the way of indicators. No evidence of unusual talent in childhood was found in outstanding adult instrumentalists (Sosniak, 1985) and in musically gifted children (Sloboda \& Howe, 1991). In another study with parents of children with varying levels of musical accomplishment, the only musical behaviour identified in the early years was singing from an early age (Howe, Davidson, Moore, \& Sloboda, 1995). In a group of adult musicians (Sloboda, Davidson, \& Howe, 1994), the recollection of early musical memories showed that a 
majority remembered "deeply felt and intensely positive early experiences to the 'internal' aspects of musical events, which seemed to lift them outside the normal state of awareness" (p. 353).

A perspective on skill acquisition of expertise argues that the main factor behind expert performance is the amount of extended and optimally distributed deliberate practice (Ericsson, Krampe, \& TeschRömer, 1993). Deliberate practice is characterized by carefully structured activities in order to improve performance. This solitary practice application involves high motivation and extended effort deriving from full attention. To sustain concentration (and by extension to improve skill level), the duration of practice sessions should be kept to a reasonable length. The Ten-Year Rule, established in empirical research, suggests that it takes approximately ten years of this kind of intense study and practice to attain international proficiency (see also Simon \& Chase, 1973). Later, Ericsson et al. (1993) confirmed that expert performance requires a decade of intense preparation across domains, for example music composition, sports, science and the arts. In a group of expert violinists, the group of the most accomplished violinists were estimated to have spent over 10,000 hours in deliberate practice by the age of 20. A group of amateur pianists, on the other hand, reported averaging 2,000 hours by the same age.

Sternberg (1996) points out biases in the conceptualization of deliberate practice. The construct, which is based on retrospective data, measures 'time spent wisely', and it should be seen as a proxy for a number of variables such as motivation and talent. Sternberg agrees that hard work or deliberate practice is necessary for the development of any artistic expertise, but believes that hard work alone does not account for expert skill.

\section{Features of musical development}

The perspective on musical development mainly concerns musical education up to graduation for the student. Less is known regarding how to maintain a high standard. From a learning perspective, literature is lacking about how to increase the specific knowledge for the professional artist and musician. In a review of practice research, Hallam (1997) presents a model indicating factors that may influence 
the practice process, factors that may determine the outcome of musical performances. Learner characteristics are described as motivation, personality, learning style and self-esteem. Factors in the learning environment include teacher characteristics and interventions, home environment and parental support. It is also vital that appropriate task requirements are accessible in terms of the nature of the task, instrument characteristics and repertoire. In this model, the practice process is directly related to learning outcomes such as affect, level of achievement level, and level of communication with an audience.

From a learning and student perspective, Sosniak (1985) distinguishes three phases in the learning process using interviews with professional concert pianists and their parents. In the first phase, the child is engaged in playful musical activities with music. In phase II (10-13 years of age), the child is involved in a systematic study of music with the tutelage of an expert teacher. In this phase, technical as well as expressive aspects are addressed. In phase III (16-20 years of age), the adolescent is entirely dedicated, both emotionally and practically, to improving their musical skills. The teacher serves as an admired role model. In a later publication, Sosniak (1990, cited in Moore, Burland, \& Davidson, 2003) draws the attention to the role of peer influence during the school years. Peers, particularly older students, serve as standard bearers for other students, providing students with a relative way to conceptualize their own skill level.

From a life span perspective on the musical profession, Manturzewska (1990) bases her research on qualitative data reflecting musicians' functioning from early childhood to late adulthood. Professions like pianists, violinists, and singers in the classical genre are represented. The professional life of musicians can be understood as a sequence of successive, overlapping and partially cumulative developmental stages. This life span overview shows that the musician's career comprises kinds of work assignments other than only the performances they do over the years. Each stage has a critical period characterized by sensitivity for a certain type of learning of various skills, knowledge, attitudes and habits that are essential for resolving the particular developmental task of the specific phase. Manturzewska suggests that there are altogether six stages over the life course. In the first stage (up to 6 years), the individual displays 
acoustic-musical interests and enjoys being involved with music. In stage II (intentional, guided music development, age 6-14 years), there is a shift from the need to play to a desire to learn music. The individual asks for music lessons. If the family does not have musical background, the individual might have to struggle and be very motivated in order to be heard. In the third stage (formation and development of the artistic personality, age 12-24 years), adolescents and young adults search for models and desire to share artistic ideals with others. The transition from music conservatoire to professional life gradually takes place. After having established oneself in the professional community, stage IV (professional stabilization, age 30-50 years) is characterized by the greatest artistic and performing activity in terms of collaborations, concerts and recordings. Musicians begin to expand their repertoire and performance technique. Towards the end of this stage, the musicians change interest from individual career concerns to general social issues such as pedagogical tasks. In stage $\mathrm{V}$ (teaching phase; at age 55-65 years), singers and violinists often end their concert performances. The interest in social issues is enhanced. Their teaching achievement is optimal during this stage. Musicians who have attained great career success are found in representative functions such as taking part in juries of musical contests, and they are offered honorary assignments. In stage VI (retreat from professional activity, age 70-75 years), the musicians retire from professional life, although some of them continue teaching.

\section{Social factors}

The acquisition of expert skills also critically depends on access to relevant social support. In childhood, the single most important variable in developing a child's musical interest is providing a stimulating environment and responding to child's musical reactions, if and when they occur (Sosniak, 1985; Howe \& Sloboda, 1991). Parents of gifted children can influence their children's early musical development. The parents typically have high expectations and also model hard work and high achievement (Sosniak, 1985). This does not necessarily mean that the parents are engaged in music themselves, professionally or otherwise. However, musically skilled children are often introduced to music because of the musical interest of their 
parents. Parents are often more directly involved with respect to music and athletics than for the visual arts or academics. These parents require their children to practice. The parents also take an active and financial role in lessons, rehearsals and concerts. Besides the influence of parents, the role of the teacher for the development is also highly significant. From childhood through late teens, the relationship with the teacher changes. In the early stages of learning, talented children remember their teacher being generous and enthusiastic, and that just having fun together was relevant in the early stages of learning. In the second stage, the children value the constructive criticism of their teachers and their support for engaging in various musical activities. The goal for music training switches to learning precise skills and to meeting more objective standards. In the third stage, it is important for the teenage student to share the mutual dedication for music with the teacher.

A student's education is important for their development. There is a positive relationship between the teacher's involvement and practice amount (Sloboda, Davidson, Howe \& Moore, 1996). The findings indicate that students who report the highest amount of formal practice tend also to have the most weekly time in the presence of a teacher. Additionally, the musical institution may have an influence on the decision to pursue a career or not for (Burland, \& Davidson, 2002). Some students find music competitions a negative experience or learning music as intellectually boring. Others keep their enthusiasm and subsequent musical creativity.

\section{Motivation}

The perspective on aspects of musical processes, in this case motivation, has centred on children and how they come to value learning to play an instrument and remain persistent in their ambitions over the years. This line of research mainly applies a cognitive perspective (see Hallam, 2002; O’Neill \& McPherson, 2002). Unfortunately, research about the professional performer and motivation appears to largely be lacking. Ericsson (1997) states that "our knowledge about the gradual acquisition of expert performance during decades of high levels of daily practice is greatly increased, but the motivational factors that maintain the daily efforts to keep 
improving continue to be largely a mystery" (p. 45). Certain forms of motivation are probably indispensable for artistic and professional development.

A musician is not conceivable without his or her instrument. The choice of instrument was often initially made by the parents, but for the continuing involvement in music activity, the individual must find the quest rewarding. The relation to the instrument is intimate and emotional, as the musician is concerned with how he or she can express himself or herself through the particular instrument (Ostwald, 1992; Pruett, 1989). The quality of the relationship is also critical. The sound, the physical contact and the possibility to express oneself through the specific instrument, for example tuba, viola or voice, have to meet the preferences for the child and the adult in order for them to preserve the interest over years. Another motivational feature is the distinct social form of musical interaction. Some individuals might prefer to play in a group, and others might be more suited to perform solo in front of an audience. In addition, the desire to play music is related to the musical values of the audience. The musician may depend on meeting these demands in order to be competitive.

\section{Practice strategies}

The acquisition of performance skills can be studied from several perspectives. According to the expertise approach, the start of formal practice can be compared to varying levels of achievement. Kopiez (1997) studied the start of singing lessons by analyzing biographical data from vocal students and eminent singers in classical singing. The results show that vocal students' formal education starts at a later stage (13.2 years in average) compared to singers with international reputation (8.1 years at average). Kopiez suggests that an early start is a prerequisite of developing extraordinary skills and that the high number of accumulated practice hours is a necessary feature of excellence among classical singers.

Jørgensen (2002) revised the expertise approach by looking at the relationship between the amount of instrumental practice and instrumental achievement among music conservatoire students. The regularity of practising varies moderately (on average 6-7 days a week) between the groups of vocal, instrumental, and church music students. 
The vocal students differ greatly in that they reported the lowest amount of individual practice time. Both instrumental and church music students with the grade 'excellent' are likely to practise more than students with the grade 'good' in the respective group. Jørgensen addresses the issue of how to differentiate overall progress and performance ability from progress in practice performance of one musical piece, as practice appears to improve overall development, and practising and performing a single musical piece to an audience relies on a complex interaction of variables.

Another approach is to analyze measurements of performance outcomes in relation to the level of expertise. In a study about pianists (Drake \& Palmer, 2000), expert pianists are associated with improvements in performance tempo and pitch accuracy, timing and planning of practice, whereas novice pianists made more errors and performed at a slower rate. Expert musicians attain a high level of control over motor processes and can consistently reproduce a given musical performance with its subtle variations in tempo and loudness. Williamon and Valentine (2000) infer that the identification and the use of musical structure are important features in guiding the practice and in serving retrieval, of what they previously learned, during performance.

Differences in memorization strategies for practice application have been examined among professionals and less accomplished female singers in the classical genre (Ginsbourg, 2002). The singers were asked to learn an unknown song and, intriguingly, level of singing skill was not found to be associated with extent of accurate memorization. In order to examine practice strategies, subgroups of singers were formed in respect to quality of memorization. In comparison with a group of slow and inaccurate memorizers, fast and accurate memorizers were more likely to produce music and words together in the first initial practice sessions. Nevertheless, both groups made the same amount of errors, mostly pitch and rhythm errors: however, the fast and accurate memorizers both made and corrected the errors earlier.

A third research approach considers the practice or rehearsal strategies used to prepare musical pieces. Professional musicians vary distinctly in their strategies, from rigid to more of performance-like applications (Hallam, 2001). The professionals demonstrated meta- 
cognitive skills in terms of 'thinking about one's thoughts' and had developed strategies in the areas of concentration, planning, monitoring and evaluation of performances. Similarly, advanced students at music conservatoires make use of a range of rehearsal strategies of meta-cognitive quality, yet not related to instrumental inclination (Nielsen, 2004).

\section{Expressivity}

Recent research considers the ability to perceive expressive cues in music. The tendency to listen to music with an expressive rather than an analytical ear is considered a marker of musical talent (Kirnskaya \& Winner, 1997). This way of perceiving focuses on performing qualities of music; register, timbre, loudness, articulation, and phrasing. These particular qualities are the features that carry the emotional and dramatic message of music. In this study, concert performers and untrained music lovers responded more strongly to expressive elements of musical pieces than music educators did. Especially the sensitivity to the emotional message of music might be a better indicator of musical giftedness than sensitivity to notational aspects (Winner \& Martino, 2000).

Another feature of expressive skills is the use of bodily movements in the performance. Davidson (2001) analysed body movements in singing performances with the pop singer Annie Lennox and with herself (classical singer) with the aim to study how gestures impart meaning during a performance. The body movements appear to serve many functions: to communicate expressive intentions (for example of the musical or textual content); to communicate information to coperformers (for example to take over a solo) or to the audience (for example to remain quiet); and to present information about the performer's own personality. Additionally, movements might also be used with the purpose to show off to the audience. Davidson (2001) points out the importance of the interaction between body and communicative style, musical expression of the individual, as well as the boundaries for the expressive styles that the specific culture determines. Certain movements are only meaningful within a particular context. In comparison with classical pianists whose use of body language is more restricted during a performance (Clarke \& 
Davidson, 1998), four distinct types of head movements were identified. A rocking movement was associated with the timing and structural features of the music, and with the pianist's individual reactions to the music.

Davidson and Coimbra (2001) assessed the performance of classical singers at a specialist school of music (in higher education). The jury representing professionals in the field were by and large in agreement regarding assessment grades. A qualitative analysis revealed that the jury emphasised the singer's physical appearance with respect to how the singer was able to maintain control of the voice. The control over body movements, vocal coordination, and presentation of musical content appeared to contribute to an overall impression of how successful the singer is in his or her ability to communicate and showing his or her level of artistry. The jury valued the exposure of a 'performing personality', a judgement that seemed to reflect more of projections from the jury's side and only the outward or public aspects of the personality of the individual singer. 


\section{4 \\ PERSONALITY}

This specific section aims at providing an outline of major personality traits with emphasis on trait theory and a psychobiological approach. Using this as a background, a presentation of personality traits in relation to athletic activities, creativity, and vocational interests is given.

\section{Major personality traits}

Among the many factors that may influence why individuals participate in various activities, personality characteristics and motives have been identified as important variables. In contemporary research, personality traits are regarded as a fundamental conceptual unit of personality, which connotes consistent intercorrelated patterns of behaviour (see Winter, John, Stewart, Klohnen, \& Duncan, 1998). Generally, trait theorists believe that personality traits are ordered hierarchically with major factors such as neuroticism and extraversion in the apex (Clark \& Watson, 1999). At a lower level, the descriptions are more specific and narrow. The two primary traits of neuroticism and extraversion are found in most models of temperament and personality (Zuckerman, Kuhlman, \& Camac, 1988). Eysenck (1967; Eysenck \& Eysenck, 1985) proposed a three-dimensional solution with extraversion, neuroticism and psychoticism as primary traits integrated in a psychobiological model to parallel the three dimensions. Eysenck's original psychobiological model implies that individual differences in central nervous system properties (e.g. strength of excitation, arousal) influence personality, properties that can be tested by observing how various conditional parameters differ as a function of personality. Extraverts tend to show higher thresholds for stimuli, lower thresholds for boredom and lower characteristic levels of cortical arousal. It means that extraverts seek arousal and introverts prefer to avoid arousal such as social contacts. 
Proponents of the three-factor solution have proposed a qualitatively different third primary factor in addition to neuroticism and extraversion - disinhibition (Watson \& Clark, 1993); and constraint (Tellegen, 1985). More recently, many personality researchers have agreed on a consensual and primarily phenotypic taxonomy of personality that can be described by a five-factor model (see Costa \& McCrae, 1992; Digman, 1990), a taxonomy based on extensive lexical analyses of trait terms in the normal language. This structure reflects how personality is represented in culture. The taxonomy includes traits labelled conscientiousness, aggreableness and openness to experience - besides the primary traits of neuroticism and extraversion. However, psychobiological models go beyond this approach as presented by Cloninger, Svrakic, \& Pszybeck (1993), Gray (1982) and Zuckerman (1979) with the notion that basic personality dimensions have a biological correlates, should be etiologically homogenous and have a genetic base. Researchers interested in psychobiological approaches have additionally singled out other primary traits such as determinants for human behaviour like impulsivity (Barratt, 1965; Eysenck \& Eysenck, 1977; Schalling, 1978; Schalling, Edman, \& Åsberg, 1983), and sensation seeking (e.g. Zuckerman, 1979; 1994), that have genetic determination and demonstrated biological correlates.

Impulsivity is usually described as a tendency to act rapidly without deliberation or consideration. Both sensation seeking and extraversion co-vary with impulsivity. Although impulsivity has been associated mainly with psychopathology and social disturbances (cf. af Klinteberg, Andersson, Magnusson, \& Stattin, 1993) as well as with psychoticism indicating low empathy, socialization and nonconformity (Eysenck \& Eysenck, 1985), the occurrence of impulsivity has also been demonstrated among normal groups (Schalling, 1993). The aspects of functional impulsivity and dysfunctional impulsivity indicate that functional impulsivity is related to extraversion and dysfunctional impulsivity is related to neuroticism (Dickman (1990).

Extraversion refers to a disposition of being sociable, lively, venturesome and impulsive (Eysenck \& Eysenck, 1985). However, the aspects of impulsivity are split into four factors; narrow impulsivity, risk taking, non-planning and liveliness. The more functional aspect of the impulsive disposition is called venturesomeness. According to 
Eysenck's theory on arousal, introverts and extraverts should differ in levels of activity or excitation in the cortico-reticular loop. Reviews of psychophysiological research indicate only that introverts exhibit greater reactivity to punctated physical stimulation compared to extraverts (see Stelmack, 2004b for review). This agrees with the introvert disposition to seek out solitude and quiet environments and avoid intense stimulation. In addition, there is a difference in the expression of motor behaviour. Extraverts react and take initiative faster than introverts in tasks such as a social conversations and measurements of reaction time. Extraverts are also more disposed to physical activity and sports than introverts (Eysenck, Nias, \& Cox, 1982; Kirkcaldy, 1982), showing a preference for engaging in leisure activities (see Kirkcaldy \& Furnham, 1991), most likely due to their energetic, self-assured and social disposition.

The neurotic disposition is generally described as being worried, emotionally unstable and having low self-esteem. A neurotic individual perceives the social world as threatening and problematic (Clark \& Watson, 1999; Matthews, 2004). This suggests that the individual is more likely to be motivated in his or her pursuit to maintain personal security than to give priorities to goals. Studies indicate that high scorers tend to show low professional job performance (Barrick \& Mount, 1991; Tett, Jackson, \& Rothstein, 1991), and to show low work satisfaction (Judge, Heller \& Mount, 2002). Neuroticism is also considered to be a vulnerability trait associated with various emotional disorders (Saulsman \& Page, 2004; Zuckerman, 1999). Moreover, psychophysical methods - assessment of pain and sensory thresholds have failed to distinguish neurotic individuals from extraverts in studies where sensory sensitivity was featured (Fahrenberg, 1987; Matthews \& Gilliland, 1999).

The research on sensation seeking follows the trait tradition and has resulted in a wide range of studies about risky and social behaviour, and psychological disorders (see Stelmack, 2004a for review). Sensation seeking is a trait "defined by the seeking of varied, novel, complex, and intense sensations and experiences, and the willingness to take physical, social, legal, and financial risks for the sake of such experience" (Zuckerman, 1994, p. 27). It is based on the notion that there are consistent individual differences in optimal level of stimulation and arousal. It is suggested that sensation seekers both 
endure and experience physical stimulation more intensely than lowsensation seekers. Therefore, high sensation seekers get involved in intense stimulation activities. More precisely, this particular disposition can be divided into four dimensions: (a) desire to get involved in sports or risky activities that offer unusual experiences (Thrill and Adventure Seeking); (b) seeking out novel experiences and sensations through mind and senses (Experience Seeking); (c) seeking sensation through social activities (Disinhibition); (d) intolerance for repetitive experiences of any kind (Boredom Susceptibility). Sensation seekers frequently engaged in risky but socially approved activities or sports (Hansen \& Breivik, 2001) and in pro-social risks such as being a fireman or body-guard (Gomà-i-Freixanet, 1995). Risk-taking is not a necessary requisite for sensation seekers: however, the probability for being at risk is increased, when impulsivity is combined with sensation seeking. In a group of individuals with high intellectual level and good social resources, the combination of sensation seeking and impulsivity was associated with high achievement in the military services (von Knorring, Oreland, \& Winblad, 1984).

\section{Personality and athletic activities}

Athletes might serve as a suitable comparison group to individuals engaged in professional artistic activities, especially performing artists. Both groups appear to share the achievement orientation, the dependence on physical attributes and a particular motivation for excelling in the activity. General findings indicate that artists show high levels of neuroticism and psychoticism (see Feist, 1998 for metaanalysis; Marchant-Haycox \& Wilson, 1992), whereas athletes display high levels of extraversion and low levels of neuroticism (see Colley, Roberts \& Chipps, 1985; Eysenck et al., 1982; Kirkcaldy \& Furnham, 1991).

It has been hypothesized that participants in different sports types would exhibit significantly different personality profiles. Participants in team and individual sports have been one of the most frequently used subjects because of the belief that team players would have a more sociable disposition than individual (presumably introverted) athletes. However, results have been inconsistent. High scores on extraversion have been linked to both categories; triathletes (Egloff \& Gruhn, 
1996), Mount Everest climbers (Egan \& Stelmack, 2003), squash players and volleyball players (Dowd \& Innes, 1981). A second categorization considers the level of ability or success. Lower levels of neuroticism have been associated with high competitive sports men compared to less competitive sports men (Jones \& Swain, 1992; Kirkcaldy, 1982; Maynard, Hemmings, \& Warwick-Evans, 1995; Newcombe \& Boyle, 1995). The negative relationship between sports performance and neuroticism agrees with Eysenck's arousal theory (1967). Following this, the drive stimulus qualities of anxiety might interfere with the athlete's concentration on the task. However, findings partly support this conclusion (Dowd \& Innes, 1981; Eysenck et al., 1982). For example, high scorers of neuroticism began with sport activities in order to manage negative affect and to improve recreation (Davies, Fox, Brewer, \& Ratusny, 1995), whereas high scores of extraversion seem to have a more competitive disposition for athletic efforts (Egloff \& Gruhn, 1996). Considering gender differences, overall findings indicate that male athletes exhibit lower levels of neuroticism, higher levels of extraversion and psychoticism compared to female athletes at various levels of success and kinds of sport compared to female athletes (Colley et al., 1985; Kirkcaldy, 1982; Newcombe \& Boyle, 1995). This picture reflects general gender differences in the population (see Feingold, 1994; Lynn \& Martin, 1997).

Sensation seeking in the sporting context is also viewed from a risk-taking perspective. Zuckerman (1983) classified physical sports on a risk continuum. Risk is related to possible injury of physical or psychological kind and is a function of both subjective and objective appraisal. Sports like golf, swimming and marathon running are placed on the low-risk end of the continuum, as the probability of fatalities is low. Skydiving and surfing are examples of high-risk sports and placed at the other end of the continuum due to the acute danger associated with accidents. Increased levels of sensation seeking was found in individuals engaged in high-risk sports compared to low-risk sports, athletes compared to non-athletes, and individuals in low-risk sports compared to non-athletes (see Gomà-i-Freixanet, 2004 for review). The results indicate that the aspect of thrill and adventure seeking appears to characterize the whole group of athletes, particularly individuals engaged in sports with high and medium levels of risk. 
Moreover, athletes high on the aspect of experience seeking through their mind and senses are particularly attracted to high levels of risk. The aspect of boredom susceptibility is found only to differentiate between individuals engaged in high versus low-risk sports. Finally, the aspect of seeking sensation through social activities seems to modestly discriminate only between athletes and non-athletes, and high-risk compared to low-risk sports. It might be concluded that the risky, competitive and complex nature of engaging in sports fulfils the need for stimulation for male and female athletes. Especially, high-risk male athletes are true sensation seekers. Athletes seem also attracted to the highly sociable side of sports that exercising, travels, and competitions provide. Regarding gender differences, males have been reporting to score higher on sensation seeking compared to females (Jack \& Ronan, 1998; Zuckerman, 1994). With respect to age, younger individuals have generally higher scores than older individuals (Zuckerman, Eysenck, \& Eysenck, 1978).

\section{Personality and creativity}

Personality research on creativity has aimed to identify a quality or capacity that distinguishes a creative person from a less creative person, although the assessment of creativity has to include the product of creativity. The product in terms of an idea, artwork or material in any form must meet two criteria; originality and adaptability (Simonton, 1999). An idea can be described as unique if it is the work of one individual and not of many individuals. At the same time, the idea must present a solution or achievement that can be recognized by others as novel and appropriate.

The literature has compiled a fairly secure profile of the creative personality (see Feist, 1998, 1999; Simonton, 1999). Such individuals are generally characterized as being autonomous, non-doubting and unconventional. They exhibit self-confidence, wide interests, openness to new experiences, and strong behavioural and cognitive flexibility as well as more of a risk-taking attitude. Thus, the most remarkable feature of the personality profile is its complexity. Gender differences for the creative personality seem not have been reported in the extant literature. 
A closer look at different groups representing creative endeavours shows that artists are distinguished by emotional instability, coldness and norm-doubting as compared to scientists and non-artists. In particular, elevated levels of neuroticism and psychoticism have been found among writers (Hu \& Gong, 1990; Mohan \& Tiwana, 1987), painters and sculptors (Götz \& Götz, 1979a; 1979b), only high neuroticism has been found among performing artists such as musicians, actors and dancers (Dudek, Bernèche, Bérubé, \& Royer, 1991; Marchant-Haycox \& Wilson, 1992), actors (Hammond \& Edelman, 1991), and musicians (Kemp, 1996). A possible explanation for the link between emotional instability and artists, and emotional stability and scientists might be related to the person-environment fit, in this case between personality disposition and profession. Artists are guided by feelings in working their way through a work of art, whereas scientists are guided by logic to work through their insights (Gardner, 1973). The introspective nature of artists contrasts with the more externally focused nature of scientists.

Artists and scientists, however, both exhibit low conformity and low socialization (see Feist, 1999 for review), characteristics that often are associated with independence, hostility and arrogance in interactions with others. The trait of non-conformity appears to take two different forms among the groups. Artists are prone to be lower on responsibility and tolerance, whereas scientists tend to be more orderly and conscientious. It is probable that the artists have more overt nonconformist behaviour than scientists, as findings suggest that the levels of independence and asocial traits discriminate between highly creative scientists and their less creative peers. Another finding is that the introverted nature of artists and scientists seems to be associated with independence and withdrawal. Feist (1999) suggests that this result is expected since isolation and withdrawal are prerequisites for creative endeavours.

\section{Personality and vocational interests}

A line of research has centred on the interplay between personality traits and vocational interests. Vocational interests and preferences are regarded as dispositions, as an expression of the total personality structure. This conceptualization is well represented by Holland 
(cf. 1997) who has settled on a typological description of interest domains. The types are defined on six vocational themes; Realistic, Investigate, Artistic, Social, Enterprising and Conventional (RIASEC). The key assumption is that individuals seek out environments and opportunities congruent with their personality type. A study about music teachers shows accordingly that Artistic, Social and Investigative interests were the prominent themes (Teachout, 2001). Music teachers view themselves primarily as independent, non-conforming, original, and being artistically skilled. To a lesser degree, they rate themselves being social in terms of being friendly and helpful, and the Investigative domain indicates that they are analytical and interested in problem-solving.

In the vocational literature, the five-factor model (FFM) is the second most influential person-descriptive model in recent years. Independent meta-analyses (Barrick \& Mount, 1991; Salgado, 1997) have demonstrated that conscientiousness is an overall predictor of job performance, and extraversion is a positive predictor of interpersonal performance, especially in entrepreneurial jobs. Two recent meta-analyses (Larson, Rottinghaus, \& Borgen, 2002; Barrick, Mount, \& Gupta, 2003) and a review (Tokar, Fischer, \& Subich, 1998) conclude that the FFM traits generally are related to the RIASEC types, although the magnitude of correlations is low or moderate. However, the patterns of correlations still need to be examined. In addition, gender is not found to be an important moderator across RIASEC types. Extraversion is positively related to the Enterprising type that can be explained as a fit between the extravert's disposition to be sociable and dominating in an environment that entails activities persuading and leading others. Openness to experience is positively related to the Artistic type. This individual is imaginative, intellectual, and artistically sensitive, characteristics that fit ambiguous and unsystematized activities associated with creating products or artworks. Agreeableness is positively associated with the Social type. The considerate and cooperative character will find a match in activities that involve helping people out. Results regarding associations between personality traits and the Investigative type and the Conventional type are mixed. The Realistic type and the trait of neuroticism generally are found to be unrepresented in the studies. It should be pointed out that the negative influence of neuroticism has 
been widely stated in association with work stress, autonomy, and career indecision (see Tokar et al., 1998 for review). Taking into account the overall low magnitude of correlations between traits and vocation interests, it was concluded that traits and interests are largely different constructs and cannot be substitutes for one another (Barrick et al., 2003; Larson et al., 2002).

In another study examining FFM traits and RIASEC types, De Fruyt and Mervielde (1999) demonstrate that the traits of extraversion and conscientiousness are valid predictors of employment status, whereas the vocational types are useful predictors for the nature of employment. Hogan and Blake (1999) suggest that traits describe the personality from the observer's view (such as an employer) and is an indirect measurement of reputation. On the other hand, the RIASEC model is an expression of the individual's identity, i.e. from the actor's view (such as an employee) and is a direct measurement of reputation. The difference between the observer and the actor might be exemplified with an example of a music critic for the New York Times. As could be stated in an item of a personality inventory - 'I often go to parties' would fit the personality of the music critic. In a vocational interest questionnaire, the item is articulated in terms of interest and preferences - 'I would like to be an artist'. The latter answer corresponds better to the music critic's identity. 


\section{THE PERFORMING PROFESSIONAL AND HEALTH ISSUES}

This section begins with a short description of features in the singing activity. The overall aim is to describe aspects of vocal functioning, especially for the singing and professional voice, and relate the performing activity to certain psychological and medical factors. Health issues are presented from two perspectives; a psychological view of artists' psychic health and a medical view of voice disorders. The psychological view includes performance anxiety, work-related strain and personality disorders. The medical view encompasses a number of descriptions of voice disorders in relation to the professional singers. The structure of the whole section follows how the research on these themes has been applied rather than based on underlying theoretical constructs regarding health issues.

\section{Aspects of vocal production}

It can easily be concluded that if there is no voice, there is no opera singer. Vocal ability defines the skill level of an opera singer. It is inconceivable that musical or acting abilities would be enough for pursuing an operatic career. The professional opera singer needs to have a voice that carries enough power to be audible in large opera houses or concert halls accompanied by orchestra. The use of amplification systems is rarely accepted in the opera world. One major aim of singing training is to enable the singer to develop stamina (singing for hours without harming the voice), to enable flexibility in order express the character of the music and drama, and to be audible under these particular taxing conditions (Vurma \& Ross, 2000). In addition, timbre needs to be developed. A highly distinctive voice is more easily recognized than voices that are more anonymous or generic (Stark, 1999). This impression that a voice makes upon the audience might play a vital role for the singer's career. 
In contrast to the instrumentalist, the singer's instrument is not visible. How the sound is produced is out of sight and located in bodily functions. A short and simplified description of the vocal production would include three functional components; the respiratory system, the vocal fold and the vocal tract (Welch \& Sundberg, 2002). The human voice is produced by a periodic opening and closing of the space between the muscular vocal folds. This space (glottis) is formed by air originating from the respiratory system - that is, when the lungs contract, they move air past the vocal folds, causing the folds to vibrate. The air stream is changed into 'a pulsating air flow', the voice source, producing pure tones. The voice source is filtered in the vocal tract (the cavity from the larynx and mouth to the nasal sinus), and the output of vocal tract resonances produces formants. Both formants and the voice source are important for producing vowels and consonants. The respiratory system is responsible for variations in loudness, and the control of the vocal folds leads to an ability to change pitch. The joint activities of vocal folds and the vocal tracts form the specific timbre in a voice.

According to above brief functional description of vocal production, training in singing technique would imply, at a minimum, learning how to manipulate muscles, the respiratory system, and the vocal tract. Studies have investigated the singing process. Muscle activity was found higher in professional singers compared to student singers (Pettersen \& Westgaard, 2004). Differences were found in muscle activity in the shoulder, chest, and stomach. Thomasson and Sundberg (1999) found that highly skilled opera singers displayed consistent breathing patterns measured by lung volume behaviour and rib cage control across three performances of the same song/aria. The results from the two studies also point at inter-subject variation. The authors in the two articles suggest that the inter-subject variation in breathing patterns and muscle activation might depend on the application of distinct singing techniques. Moving from measurements of bodily functions in singing to aural indicators, acoustic parameters measuring vibrato were investigated (Sundberg, Niska Thörnvik, \& Söderström, 1998). Listeners were presented recordings of opera singers at various points in their career stretching up to three decades. Both groups reported that age were associated with vibrato parameters. However, listeners overestimated the age of young singers 
and underestimated for older singers. Effects of age are noticeable, but not necessarily as signs of singing incapacity.

Another realm of singing is the choral activity. Opera singers are soloists and the individual expression is stressed, whereas singing in a choir involves focusing on taking part in a uniform sound. Furthermore, depending on whether the activity is related to leisure time or professional pursuit, the effects on well-being might be different. The benefits from engaging in choral activity as leisure indicated experiences of well-being in terms of improved mood ('feeling happier' and 'awake and alert') and stress reduction (Clift \& Hancox, 2001). Choral singers enjoy learning how to use body posture and breathing capacities in a more adaptive way. In the professional choral activity, a high level of occupational strain was found among elite opera choral singers (Kenny, Davis, \& Oates, 2004). The opera choral singers demonstrated considerably higher trait but not state anxiety. However, they used more personal resources compared to a normative sample. The results led to the suggestion that earning one's living in an environment of constant evaluative threat might increase the artists' baseline anxiety.

\section{A psychological view of artists and health}

Performance anxiety is a widely spread phenomenon among performing artists (Marchant-Haycox \& Wilson, 1992), actors (Wilson, 2001), orchestral musicians (van Kemenade, von Son, \& van Heesch, 1995) and music students (Dews \& Williams, 1989; Wesner, Noyes, \& Davis, 1990). However, most artists learn to tolerate the symptoms. The actual prevalence is difficult to estimate as both samples and measurements of performance anxiety vary in the studies. The constructs of performance anxiety have in common the focus on the strong, often incapacitating fear of performing in public divided in items assessing affective, cognitive, physical and behavioural responses of the individual (Steptoe, 2001). Wilson and Roland (2002) discuss the overlap of symptoms between performance anxiety and social phobia/anxiety. The essential feature of social phobia is a "marked and persistent fear of performance situations in which embarrassment may occur", manifested as an anxiety response (American Psychiatric Association, 1994). The individual fears the scrutiny by other persons 
or is exposed to unfamiliar persons. Anticipatory anxiety can occur just before the anxiety-provoking situation and as well far in advance of the event. The event is anticipated with dread and/or endured with anxiety or distress. Performance anxiety should be diagnosed as a social anxiety when the individual shows marked distress or the anxiety leads to significant impairment. Investigations indicate that fear of social situations is positively related to performance anxiety (Steptoe \& Fidler, 1987), and that high levels of social anxiety are positively associated with a distorted perception of one's own voice (Lundh, Berg, Johansson, Nilsson, Sandberg, \& Segerstedt, 2002). Lundh et al. confirm a cognitive distortion hypothesis where highly socially anxious individuals would rate the quality of their own voice more negatively compared to the ratings of independent observers. Moreover, the self-image might be affected by incapacitating symptoms, as the loss of ability to engage in music-making is a threat to the professional and private self (Zaza, Charles, \& Muszynski, 1998). The close identification with the music-making qualities and functioning cannot be separated from the private self or vice versa. Musicians often describe their symptoms in musical terms; loss of range, tone quality or reduced endurance (Brandfonbrenner \& Kjelland, 2002). Singers are significantly much more prone to worries and anxiety regarding the quality and functioning of the voice than non-singers (Sapir, Mathers-Schmidt, \& Larson, 1996). Singers visited physicians more frequently and reported higher level of abusive speech habits compared to non-singers: however, there was no difference regarding general affective states between the groups. This particular study attests to the unique attitude and heightened sensitivity of singers regarding voice, singing and vocal health.

From a psychodynamic point of view, Gabbard (2000) draws the attention to the performer's fear of exposure before an audience. The artist is focused on the details of the performance on a conscious level. Unconsciously, however, it could be the body, thoughts and emotions that are in object of public evaluation for the artist. Physical incapacities or psychological notions of having an inappropriate attitude or emotions might evoke shame and embarrassment. Similarly, the term of perfectionism can be applied in relation to performing anxiety. Both self-oriented (trying to live up to standards set by oneself) and socially (trying to meet expectations of significant others) 
describe perfectionism that are positively associated with performance anxiety (Mor, Day, Flett, \& Hewitt, 1995). The underlying assumption is that anxiety occurs when the individual perceives a disparity between the ideal and the actual self.

The expectations of high achievement are voiced in an autobiography by the opera singer Jussi Björling (1994). He experienced that the public acknowledgement and success was followed by gossip, pedantry and often unfair criticism. He questioned if the way his life was made public - "every little detail was examined" (p. 16) was the price to pay for success. It is possible to interpret Björling's reaction as a personality disposition, although at the same time it might be regarded as an evidence of work-related strain or an interaction of both factors. The connections between work-related strain and somatic symptoms among artists have gained scientific interest. Demands on consistent high performance are associated with hearing problems (Chesky \& Henoch, 2000; Kähari, 2002) and musculoskeletal problems among classical musicians (Middlestadt \& Fishbein, 1988). Orchestral musicians report a low sense of autonomy or personal control compared to persons in other service occupations (Theorell, Alberg-Hultén, Sigala, Perski, Söderholm, Callner, \& Eneroth, 1990). Other influential factors on work-related strain are reported such as irregular working hours, long periods away from home on tour in the groups of among popular musicians (Cooper \& Wills, 1988; Raeburn, 1999, 2000), and dancers (Hamilton, Kella, \& Hamilton, 1995).

According folklore, creativity is linked to certain psychological dispositions. Indeed, the creativity and the mad genius controversy have ancient roots. By the time of Plato and Socrates, it was believed that poets communicated with the gods through madness and sacred enthusiasm (Jamison, 1993). Divine inspiration could only occur in connection with specific states of mind. Still today, the subject draws attention. A meta-analytic review of personality traits among creative individuals indicates that the heterogenous group of artists has a personality disposition towards non-conformity, emotionality, toughmindedness, and self-assurance (Feist, 1998). Mental illness and eminent creative achievement among $20^{\text {th }}$ century men and women were explored using biographical data (Ludwig, 1995). The incidence rates for personality disorders among creative persons are mixed. It 
seems as if the incidence rates depend on the prevalent mode of creative expression. Poets, writers, actors, composers and artists tend to suffer from high rates of personality disorders, whereas architects are more similar to the scientists in their lower susceptibility. The prevalence of mood disorders and anxiety is increased among artists compared to other groups. Jamison (1993) examined the link between the artistic temperament and manic-depressive illness, finding that artists show a greater variety of personality dispositions and also disorder. This fact does, however, not mean that a deviant personality profile is necessary for artistic or creative work. The artistic personality often provides a fine illustration of how supposed psychological weaknesses can sometimes be converted into a form of optimal functioning. Creative individuals can be characterized by an unusual mix of personality characteristics (Post, 1994), and it should be stressed that they excel by means of their abilities, drive and industry. Ostwald, Avery and Ostwald (1998) note the disparity between higher rates of psychopathology among artists involved in verbal expression, and lower rates of psychopathology among performing artists using non-verbal expression. Referrals to a clinic for performing artists show that anxiety and depression are the most common reasons for seeking treatment. Major problems with anxiety are performance anxiety, panic attacks or anxiety related to history of trauma. Depressive episodes concur with loss of a person, a major life stress and severe disappointments such as career setbacks. For example, a violinist became depressed because she had to refrain from playing a concerto. She had developed an overuse disorder, i.e. pain and inability to play well, as a result of excessive playing. Furthermore, the concerto was written specifically for her, and she felt very guilty towards the composer because she could not perform the piece in concerto. Because of this loss of ability and insecurity about playing at a high level, she sought treatment.

\section{A medical view of the professional singing voice}

From the view of medical science, the manifestations of somatic symptoms are identified and the psychological issues are reasonably bearing less weight, although the importance of relating vocal dysfunctions to the emotional state of the individual is being 
underlined (see Milutinovic, 1996; Morrison \& Rammage, 1993). Professionals who depend on their voice - singers, politicians, attorneys and educators - depend on vocal endurance and quality for their livelihoods. Their voices might show signs of impairment for many reasons. A medical examination will show if the cause of the disability or dysfunction is non-organic or organic (cf. Sataloff, 1998). Anomalies in vocal quality can suggest various medical conditions and should be taken seriously, since minimal voice disturbances may occasionally be the first signs of serious neurological disease. It is important to establish the aetiology of the voice problems for proper treatment.

Some studies have investigated vocal impairment among individuals engaged in singing activities, but the findings are mixed due to the lack of comparison groups and the diverse application of measurements. Measurements often tap problems with the speaking voice and not the professional voice. The few findings point towards that the professional singers have a different profile of reported symptoms compared to the non-professional singers, and that the speaking voice is rarely the main problem for professional singers compared to non-professional singers. For example, professional singers appear to exhibit a different profile of symptoms of voice disorders compared to recreational singers (Rosen \& Murry, 2000). Common diagnoses in both groups are vocal nodules, polyps or vocal fold cysts, yet the professional singers report high rates of symptoms in relation to the diagnoses. Professionals report less problems with the speaking voice than recreational singers, although the emotional impact related to voice problems was higher among professionals than recreational singers. A study of voice quality parameters among young adult choral singers demonstrates the occurrence of symptoms with hoarseness, fatigue, and change in voice range (Tepe, Deutsch, Sampson, Lawless, Reilly, \& Sataloff, 2002). Another study indicates that vocal impairment regarding the speaking voice is reported by around $70 \%$ of professional singers and non-singers (Phyland, Oates \& Greenwood, 1999). The most common symptoms are hoarseness, voice-fatigue, tickling/choking and pain in the throat. Twice as many professional singers than non-singers were diagnosed with vocal disorders during the last 12 months. The most frequent diagnosed condition is laryngitis followed by oedema/swelling and voice 
problems of no known medical reason. Almost a third of the professional singers were unable to perform due to 'voice problems' during the previous year.

Voice disorders can be diagnosed from a functional perspective. Functional disorders occur due to inappropriate use of the voice. Misuse/overuse of the speaking voice and inappropriate technique are reported as the main causative factors among adult singers (Hogikyan, Appel, Guinn, \& Haxer, 1999). From a clinician's view, excessive muscle tension in the tongue, neck and larynx are the most common errors the manifest due to poor singing technique is (Sataloff, 1998). Inadequate abdominal support and the use of excessive volume are two other complications. Sataloff (1998) notes further that vocal impairment among professional singers is usually caused by infrequent singing lessons and extreme schedule demands. Another factor is 'oversinging'; i.e., the singer has suddenly increased his or her daily singing practice from 1-2 hours to several hours per day due to an upcoming performance within a fortnight (Rosen, Heuer, \& Sataloff, 1998). Moreover, the singer has to adapt to age-related vocal changes that appear; for example the general muscle tone decreases with age, affecting the vocal coordination (Sataloff, 1998). The singing technique and choice of repertoire need to be adjusted to face these changes.

Another category of voice disorders is classified as being of psychogenic origin. The diagnosis of a psychogenic disorder is given when laryngological examination demonstrates normal physical structures, and when psychological factors are present that could cause or be reactive to the voice problems. Common examples of psychological factors are anxiety, depression, conversion reaction and personality disorder (Aronson, 1990). Psychogenic voice disorders might be represented by a range of presentations such as musculoskeletal tensions disorders and conversion disorders. Patients often reported that interpersonal conflicts in their family or at their work coincide with their physical issues. Other stressors are related to work strains and complicated life changes (Andersson \& Schalén, 1998; Rosen et al., 1998). In this connection, it is interesting to note that microtremors in the vocal muscles were associated with a stressinduced variable in an experimental study (Mendoza \& Carballo, 1999). From clinical practice, Rosen et al. (1998) conclude that as 
singers rely on their vocal ability for a living, they are very susceptible to emotional distress singers if they detect any impairment in their communicative function. The vocal ability is considered an ideal product of the self rather than an equivalent to the self. Reactive anxiety or depression might follow vocal impairment. Singers experience both psychological and physical stressors that might interfere with their performances. Performance anxiety is one of the major stressors. The singers have to cope with being exposed to an audience under taxing conditions. It is also likely that patients with organic voice disorder will experience depression and anxiety as a consequence to the loss of vocal quality and ability. The change in emotional state might as well have an impact and mask neurological manifestations; for example dystonias are related to both neurologic and psychogenic origins. Psychogenic voice disorders are generally considered difficult to treat and need the interventions from interdisciplinary team with medical and psychological experience. It is unclear why some people react with explicit vocal disorders as a result of emotional stress. House and Andrews (1987) suggest that these individuals display a "conflict of speaking out". This proposition takes into account the symbolic elements of the voice as a mode for human communication. Vocal disorders would then be regarded as an incapacity for expressing one's emotions verbally. 


\section{RESEARCH OBJECTIVES}

The overall purpose of the present thesis is to examine various factors and processes associated with the artistic profession and development of opera singers. The main objectives in the studies are to investigate health issues, skill acquisition process and personality characteristics. The initial pilot study identifies health-related issues related to the professional activity of opera singers. Health issues are conceptualized as descriptions of psychological and somatic symptoms linked to associated behavioural strategies. In addition, motivation factors are examined. In Study II, the psychological and physiological effects of singing lessons are studied in relation to amateur and professional levels of singing experiences. The experience and meaning attached to singing lessons are considered important for their effect on the emotional state. In Study III, features in the skill acquisition process in higher opera education are investigated. The study is designed to provide a descriptive model of the formative process associated with formal education. Study IV assesses personality characteristic among elite students in opera and business. The two groups of students represent elite educations and at the same time separate educational inclinations, an artistic versus a traditional academic setting, which is assumed to be reflected in certain personality dispositions. 


\section{METHODS AND MATERIALS}

\section{Study design}

This thesis started out as a part of larger research project, "Expressive performance in music, dance, speech and body language", managed by the Department of Psychology at Uppsala University. The project aimed at examining the shaping and the conditions of expressive performance in various arts. Performance in music, dance and artistic speech was studied with a view to discover commonalities and differences among the art forms in order to clarify favourable and unfavourable conditions for expressive performance. In contrast, the current research focused on the individual artist (the opera singer) and aimed to identify factors and processes operating in the artistic profession and development of opera singers.

As previous research about opera singers and their artistic process was lacking, a naturalistic inquiry strategy was selected with the purpose of exploring factors and processes in their natural settings (Patton, 1987). The number of opera singers in Sweden allowed the researcher to conduct a population study. Qualitative and quantitative data were collected separately and also in combination. Specific questionnaire and interview guides were constructed. Standardized and well-established questionnaires were used in one study. The data analyses of the qualitative studies were guided by grounded theory (Strauss \& Corbin, 1990). The data analysis of the quantitative data examined associations between health-related variables as well as differences between groups of individuals (students and gender). An overview of measurements, study groups and response rate is presented in Table 1.

\section{Study groups}

The main group for investigation was opera singers. Three subgroups were examined more closely - opera students, professional opera singers and amateur singers in the classical genre. Two groups of 
students representing traditional academic settings were also included as comparison groups. All samples entailed healthy subjects.

In the pilot study (Study I), the sample involved professional opera singers, a sample that represented qualitatively different professional experiences ranging from younger to older opera singers, from opera students at the end of their education to world stars. In the qualitative part of the study, 8 females (age range 27-65 years) and 7 males (age range 31-55 years) participated. In the quantitative part, 25 females (age range 21-35 years) and 24 males (age range 21-65 years) participated. Additionally, a group of significant persons $(n=15)$ in allied professions or who had regular contact with singers in various situations were interviewed, but the data are not presented here.

In Study II, the sample consisted of amateur singers (8 amateurs; 6 females, 2 males, mean age 40.2, age range 28-53) and professional singers (8 professionals; 4 females, 4 males, mean age 36.4, age range 26-49) in the classical genre.

In Study III, the sample consisted of opera students at the end of their education at an opera college $(n=8 ; 5$ females, mean age 29.4; 3 males, mean age 26).

In Study IV, the samples comprised opera students ( $\mathrm{n}=62 ; 36$ females, mean age 27.9; 26 males, mean age 27.4) and business students ( $\mathrm{n}=68 ; 31$ females, mean age 25.4; 37 males, mean age 26.5) in elite university colleges. The majority of the students in the two groups was in their first or second year of education. Moreover, data representing a norm group an ordinary junior college were included $(\mathrm{n}=911 ; 407$ females, 504 males, age range 17-20 years) (Levander, 1988). 


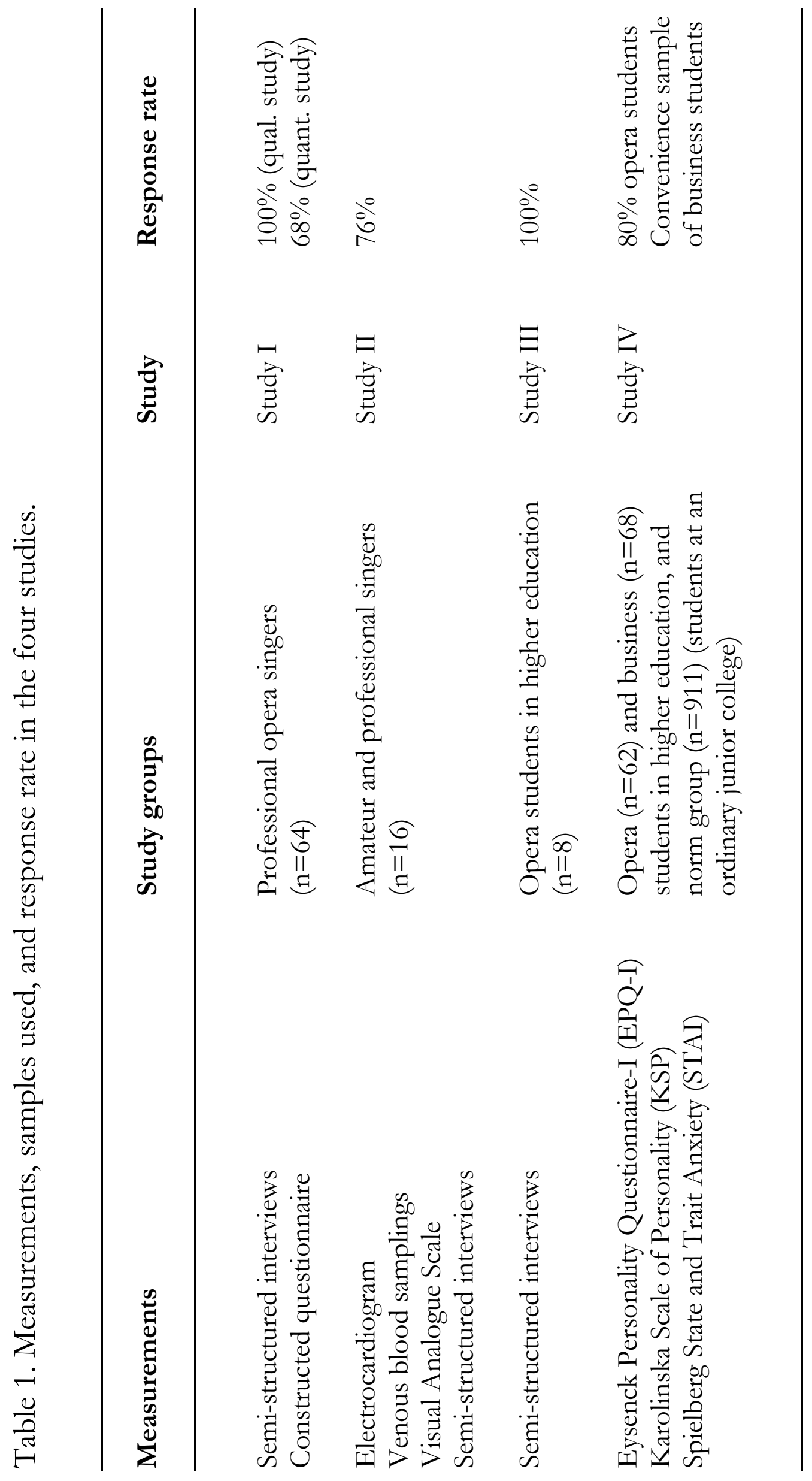




\section{Inclusion procedure}

In the pilot study (Study I), the inclusion of professional opera singers followed guidelines according to grounded theory (Strauss \& Corbin, 1990). The author asked participants to suggest professional opera singers according to inclusion criteria such as gender, age and professional experience. The inclusion of subjects followed successively to a point when collecting additional data was counterproductive; i.e., when theoretical saturation was attained. A similar procedure was adopted to find significant persons in allied professions or who had regular contact with singers in various situations. The author could immediately check if the recommended subjects in both interview groups matched criteria and it was shown that the subjects had very good knowledge of the professional pursuit of colleagues in the opera field. Risks for selection bias were limited. In order to assure confidentiality and to avoid possible bias, the author did not reveal by whom the interview person had been suggested.

In Study II, in the initial phase of sampling of singing teachers, one of the authors contacted significant persons in the particular field for recommendation of singing teachers according to certain criteria; licensed teachers of classical singing for at least five years and having previous professional experience of singing. Thereafter, the singing teachers recruited singers among their students according to criteria; age 25-55 years and must have been attending lessons with the teacher in question for at least half a year. Amateur singers were operationally defined as persons attending singing lessons for non-professional reasons during their leisure and did not earn money from singing activities. Professionally singers were defined as earning at least 25\% of their total salary from singing. The singers were checked for cardiovascular disease or medication and pregnancy which would have affected the assessments.

In Study III, all students in the third year of their studies at an opera college were invited to participate in the investigation. The inclusion of the whole class depended on the circumstance that the students were the only group of third year opera soloist students available in Sweden at this time.

In Study IV, the inclusion of subjects differed in the two samples of students representing elite educational settings. Data were collected at two opera colleges over 6 years, as the population is very small. All 
opera students were approached and invited to participate, with the exception of two classes of students. The group of business students comprised a convenience sample. The data collection was performed on three occasions at the premises of the business college. The business students were contacted by their teacher. They were also requested to ask other business students at the college to participate in the investigation. Moreover, in order to apply a normative approach, previously sampled data representing norm scores were included, consisting of students at an ordinary junior college.

\section{Response rate}

It is noteworthy that the response rate was generally high across the studies. In the initial pilot study (Study I), altogether 33\% of the population of professionally active opera singers in Sweden participated. In Study II, participation rate was $75 \%$ and in Study III, no student rejected the invitation to participate. In Study IV, 80\% of the opera students agreed to participate and the group of business students comprised a convenience sample. It was hardly expected that this high number of singers would agree to participate across the studies, as they are subject to public exposure in their work and showed concern regarding the risk of being identified, particularly by other professionals within the opera world. In Study I and II, the choice to recruit by recommendation probably influenced the high participation rate and the general lack of selection bias.

\section{Measurements}

\section{Qualitative measurements}

In the pilot study (Study I), a semi-structured interview guide was created with the aim to identify problematic areas in relation to the artistic pursuit of professional opera singers. The interview data served as base for the construction of a questionnaire to be sent to another sample of professional opera singers. The semi-structured interview guide involved issues such as health problems of psychological and somatic concern, coping strategies, motivational factors, specifics of work situation and singing activities. The application of open-ended questions aimed at capturing the specific points of view of each 
individual without predetermining those points. The focus was on the process of generating theory rather than a particular theoretical content according to grounded theory (Strauss \& Corbin, 1990). The interviews with other persons in allied professions in the field involved open-ended questions related to the person's professional experiences with opera singers.

In Study II, two modes of qualitative data were collected (yet together with quantitative data, see next section Quantitative measurements). Emotional states were assessed by self-reports on 5 VAS scales (Visual Analogue Scale) with emotional extremes; sadjoyful, anxious-calm, worried-elated, listless-energetic and tenserelaxed. The construction of the VAS scale was specific for this study, but its design was standard. The scales were horizontal, ungraded and anchored at both ends by vertical lines labelled as the extreme boundaries of the variable to be measured. In addition, a semistructured interview guide was created with the primary aim to assess the subjects' experiences with singing lessons. The interview had the format of open-ended questions in order to obtain each subject's specific emotional experience from the immediate singing lesson and also to obtain data about their engagement in singing activities in general.

In Study III, a semi-structured interview guide with open-ended questions was created aiming at examining their musical background and experiences related to learning and artistic development during the time at the opera college. The overall aim of the design was to provide data for creating a descriptive model of the artistic development during the years at the opera college. Questions regarding the learning experiences and current artistic development involved strong emotional singing experiences, significant singing performances, examples of learning experiences, motivation factors, the individual's artistic strength and weaknesses, and the definition of artistic development. Questions regarding musical background covered start of singing lessons, instruction on other instruments, musical activity, family background as well as educational and professional background (music and non-music). Further questions concerned expectations about the education, significant projects in terms of staging opera scenes and significant persons. The students provided their age and 
birth place. In a follow-up five years after the completion of the study, the students described their professional standing.

\section{Quantitative measurements}

In Study I, a questionnaire was constructed based on the interview data from the same study. The questionnaire comprised 138 items with two open questions as well as demographic data and professional status. The contents of the questionnaire covered health-related aspects of particular concern for the subjects. Mainly two variations of response format were used. For the assessment of health problems, several parameters were defined - addictive behaviour, depression, the relation to the voice, hypochondrical tendencies and worry about others' opinions. The scales ranged from (0) "do not agree at all", (1) "do agree to some degree", (2) "do agree moderately", (3) "do agree rather much" and (4) "do agree very much". For health-promoting activities, the scale included the following gradations; (0) "never", (1) "rarely", (2) "sometimes", (3) "often", and (4) "always".

In Study II, two types of physiological measurements were performed. Assessments of heart rate variability (HRV) gave indications of changes in the electrical conductance system or a shift in the sympathetic/parasympathetic balance to the sympathetic side. The assessments followed by applying an electrocardiological monitoring equipment (portable ECG recorder) on the singer's chest. The ECG registered HRV during the whole investigation. Other physiological assessments involved the level of serum cortisol and serum prolactin (stress hormones), Tumour Necrosis Factor alpha (TNF-alpha, a cytokine) and oxytocin (a pituary hormone). Serum cortisol indicates level of arousal. Serum prolactin increases in stressful situations and is related to states of powerlessness. The TNF-alpha increases in stressful situations and in inflammatory conditions. Oxytocin increases in certain pleasurable situations and interacts with the relief of pain and anxiety. Because endocrinological changes show over time, the second venous blood sampling was collected at the very end of the investigation.

In Study IV, psychobiological correlates of personality were assessed by Karolinska Scales of Personality (KSP), Eysensk Personality Inventory-Impulsiveness (EPQ-I) and The State Trait 
Anxiety Inventory Scale (STAI). The KSP is a self-report inventory comprising 135 items grouped into 15 subscales (Schalling, Åsberg, Edman, \& Oreland, 1987). All items are responded on a four-point scale; (1) "does not apply at all", (2) "does not apply particularly well", (3) "applies fairly well", and (4) "applies completely". The inventory has been developed in order to measure certain factors underlying psychopathology and is not intended to cover the whole personality. The scales are constructed on a rational-theoretical basis rather than on empirical techniques. The scales have later been subjected to psychometric analyses. The subscales relate to four higher-order personality factors; a) anxiety-related scales (somatic anxiety, muscular tension, psychic anxiety, psychasthenia, inhibition of aggression); b) aggression-related scales (indirect aggression, verbal aggression, irritability, suspicion, guilt); c) introversion/extraversion-related scales (impulsiveness, monotony avoidance, detachment); and d) conformitynon-conformity-scales (socialization, social desirability). The second personality inventory, the EPQ-I, measures the primary personality factors - extraversion, neuroticism, psychoticism (Eysenck \& Eysenck, 1975), as well as impulsivity from the ImpulsivenessVenturesomeness-Empathy Inventory (IVE; Eysenck \& Eysenck, 1978). The inventory consists of 114 items in yes-no format. The EPQ is based on psychobiological theory of personality. Moreover, the measurement of STAI is a 40 item self-report inventory aiming at assessing stable differences in anxiety proneness (Spielberger, Gorsuch \& Lushene, 1979). The items are formulated as statements to which responses indicate degree of agreement; (1) "not at all", (2) "somewhat", (3) "moderately so", and (4) "very much so". The STAI includes both state and trait anxiety, where state anxiety refers to a transitional subjective emotional state reflecting heightened arousal. Trait anxiety refers to stable individual differences making the individual prone to perceive a wide range of situations as threatening (Spielberger, Ritterband, Sydeman, Reheiser, \& Unger, 1995).

\section{Procedures}

In Study I, the interviews with opera singers and persons in allied professions were performed individually at a quiet and comfortable place of choice by the subjects, preferably at their work places and at a 
few occasions in their homes. The duration of the interviews varied between 1-2 hours. The author was also invited to observe a live opera performance (back stage) at a major opera house. Before the publication of the data, the opera singers were asked to approve the use of their quotations. The collection of data from the interviews with persons in allied professions in the opera field aimed at giving a wider perspective of the professional opera world as well as a means to validate the data from the interviews with the professional opera singers. However, the data were not presented in the study. All interviews were conducted by the author. In the second part of the study, the questionnaires were sent to the home address of the singers and returned by mail to the author.

In Study II, the investigations of singing lessons were performed individually and by the same researcher, a nurse. The researcher, the subject and the singing teacher met at the singing studio of the singing teacher or at the school of the student or the singing teacher. The procedure started by applying the ECG monitoring equipment on the subjects. Thereafter, two kinds of assessments were performed before, and this procedure was repeated after the singing lesson. This included the first venous blood sampling by the researcher and that the subject scored his or her emotional states on VAS scales. Next, the subject and the singing teacher performed a 45-minute singing lesson. Directly afterwards, the subject rated a second time his or her emotional states on VAS scales. After this, the subject participated in a semi-structured interview without the presence of the singing teacher. The investigation ended with the second venous blood sampling. The duration of the investigation was about 2 hours for each subject. The singing lessons took place from 9 am to $7 \mathrm{pm}$. Four amateurs had singing lessons in the evening, but none of the professionals.

In Study III, three interviews were conducted individually with the subjects at a quiet and comfortable place of their choice; at their work places, in their homes or at the author's work place. The interviews lasted about 1 hour. All interviews were conducted by the author.

In Study IV, in presence of the author the groups of opera and business students filled in questionnaires at the premises of their respective college. 


\section{Data analyses}

In Study I, all interviews were tape-recorded, transcribed and analyzed by the author. The analysis of the interviews followed basically the notion of grounded theory. An inductive and comparative strategy was applied for the quotations of the subjects. A parallel coding procedure emerged, where data were simultaneously organized in smaller units as well as in broader descriptions of properties. Another guiding tool for data investigation was the interview guide that summoned up concepts on a higher hierarchical level. For the quantitative study, the distributions of all scores were inspected for deviations from normality. The significance level was set to alpha $<.05$. The items were calculated as means of the item raw scores. Within group analyses were made using Pearson correlations. Between group analyses were made using $t$-tests. Dimensional accounts were examined using factor analysis, Varimax rotation.

In Study II, the two-tailed significance level was set to alpha <.05. Two-way analysis of variance was used for variables with normal or close to normal distributions (skewness between -1.0 and 1.0). Wilcoxon signed rank paired test were used for skewed distributions. The ECG power frequency was analysed in a two-way variance analyses where pre-measurement was taken from the second (from the $5^{\text {th }}$ to $10^{\text {th }}$ minute) and from the ninth (from the $40^{\text {th }}$ to the $45^{\text {th }}$ minute) ECG investigation period, because the initial period could have been affected by the application process, and the ninth period almost coincided with the end of the singing lesson. The subject grouping was blinded to the analysists of ECG and blood samples. A limited analysis of the interview data was conducted. Single quotations were selected that represented experiences of singing lessons for the groups of amateur and professional singers. The single quotations formed key units in terms of positive and negative reactions, motivation and goals for engaging in singing lessons.

In Study III, all interviews were tape-recorded, transcribed and analyzed by the author. The data analysis was based on an inductive and comparative strategy of generating a structure of artistic development during higher education at an opera college. Interchangeably, the quotations of the subjects were analyzed and organized in both minor units and more basic properties. The interview guide was used as a similar reference point for the coding 
procedure. An important concern was directed towards the high-level conceptualizing of a developmental structure within the frame-work of change of social roles.

In Study IV, the KSP raw scores were transformed into normative T-scores based on a Swedish age- and gender-stratified non-patient sample (Bergman \& Schalling, 1981). The EPQ-I raw scores were transformed into normative $\mathrm{T}$-scores based on a large ordinary junior college sample (Levander, 1988). The distributions were inspected for deviations from normality. No skewness was found. The significance level was set to alpha <.05. The KSP, EPQ-I and STAI were calculated as means of the item raw scores. Between-group comparisons were made using two-way ANOVA F-test. Levene's test of equality of error variances was calculated. The significance level was adjusted to $\mathrm{p}<.01$ for those cases where equal variance could not be determined.

\section{Ethics}

All subjects received a letter with information about the purpose of the research, whom to contact if they had any questions later on and that the assurance that confidentiality would be respected. It was also stated that participation was voluntary and that the subjects were allowed to withdraw from the study at any time for any reason. For the qualitative studies, the subjects were informed that only quotations from interviews that were confirmed on their part would be used for publication. 


\section{OVERVIEW OF EMPIRICAL STUDIES}

The current thesis comprises four empirical studies with the aim to investigate salient features and processes in the artistic profession and development of opera singers. In the following, an overview of each study is presented with respect to its aims, major findings and discussion.

\section{Study I: Voice, soma, and psyche - A qualitative and quantitative study of opera singers}

Due to the lack of research about health issues among opera singers, it was of interest to conduct a pilot study using both a qualitative and quantitative method. The major aim of the semi-structured interviews was to gain knowledge about psychological, somatic and psychosocial problems as well as coping strategies in the professional life of opera singers. In addition, this study explores motivational factors. The study included both qualitative and quantitative measurements with two different samples of professional opera singers.

Important findings from the interviews were the emotions and behaviours associated with worry for negative evaluations by significant others of the singers' performance on stage and with the preoccupation with the voice's quality and existence. Psychological problems were found in terms of fear of vocal indisposition and a habit of regularly testing the vocal functioning by sampling tones. The singer's concern about negative evaluations from significant others was the most frequently mentioned topic and appeared to be the major psychological strain. Somatic problems were related to symptoms affecting the respiratory tract which could cause 'vocal indisposition', i.e., the inability to sing satisfactorily. Coping strategies involved primarily health-promoting activities aimed at preventing the occurrence of somatic problems and subsequent vocal indisposition. In order to cope with negative evaluations of the performance, the singers tried to dismiss criticism by evaluating it as 'unjustified'. 
Psychosocial problems concerned difficulties to maintain a family life and relations due to irregular working hours and freelancing. In addition to work strains, the singers were asked to give examples of strong emotional singing experiences during public performances. Interestingly, males gave accounts of moments associated with virtuosity and completely mastering a vocal technique, whereas females pointed out the importance of feeling a total presence on stage and expressing emotions freely in front of an audience.

In the second part of the study, a questionnaire was constructed on the results from the interviews in order to explore relationships between psychological problems, somatic problems, the relation to the voice and health-promoting strategies. The statistical analyses were based on self-ratings. Results primarily revealed consistent positive correlations between worry about negative evaluations and depressive tendencies, between somatic problems and depressive tendencies, and between worry about negative evaluations and the preoccupation with the voice's quality and existence. Analyses of gender differences were significant concerning the preoccupation with the voice's quality and existence. Males were significantly more preoccupied with the functioning of the voice than females both in terms of emotions such as fear of disposition and behaviours such as excessively testing the voice. Moreover, a factor analysis was performed on the items concerning health-promoting strategies. Five factors emerged representing; a) relaxation exercises, b) avoidance behaviour regarding alcohol, smoke and loud noise, c) use of herbal medications, b) relaxation in terms of good night's sleep, and e) avoidance behaviours in terms of avoiding situations where the singer could be contaminated by colds and infections. In conclusion, the findings suggest that there are links between the preoccupation with the voice's quality and existence, depressive tendencies and worry about negative evaluations. Moreover, health-promoting strategies were found unrelated to somatic problems.

The results indicating high levels of emotional distress need further investigation. It could not be clarified whether the distress was associated with a personality disposition or with work-related strain; however, both in the qualitative and the quantitative study, opera singers over the whole career- and age-span reported emotional states of anxiety and depressiveness. 


\section{Study II: Does singing promote well-being? An empirical study of professional and amateur singers during a singing lesson}

To engage in singing lessons is a rewarding hobby for amateur singers. However, to take singing lessons with a vocal coach is also of major importance for the development and maintenance of the vocal ability for professional singers. The present study was designed to examine beneficial effects of singing lessons in the groups of professional and amateur singers. It was hypothesized that the singing lesson would induce physiological reactions in the subjects and that the singing lesson would have effects on well-being to a larger extent for amateur singers than for professional singers. This study included measurements of physiological arousal such as heart rate variability, serum cortisol, TNF-alpha, prolactin as well as self-ratings of emotional states (on VAS, visual analogue scale) and semi-structured interviews in the groups of amateur and professional singers. The participants had been attending singing lessons in the classical genre for at least six months with the same teacher. Only singing teachers working with singing technique and expression (not with musictherapeutic aims) in the classical genre were included.

Statistical analyses of the ECG results yielded interaction effects for all three power frequencies. Professionals displayed increased heart rate variability compared to amateurs in pre and post measurements. These results may indicate that professional singers are more in control of their singing in terms of controlling breathing, muscles and other functions necessary for the singing activity compared to amateur singers. Hence, professionals showed more cardio-physiological fitness than amateurs. These results seem reasonable as professionals are welltrained as a result of years of vocal practising.

The endocrinological-biochemical analyses showed that concentrations of serum cortisol were higher in professionals than in amateurs, although no statistical significance was reached in pre and post measurements. For TNF-alpha, the levels increased for professionals and decreased for amateurs in pre and post measurements. For oxytocin, concentrations increased significantly in both groups. For prolactin, no statistical significances were found between amateurs and professionals. It appeared as if amateurs experienced more well-being displayed in lower level of stress hormones than professionals. However, the increased level of 
oxytocin points to the fact that both groups derived well-being from the singing lesson.

Results from associated self-ratings of emotional states showed that amateurs experienced more joy than professionals after the singing lesson. Both groups felt more energetic and more relaxed after the singing lesson. Group differences were shown in a higher level of elation for amateurs and a slight decrease for professionals. The interview data revealed that professionals reported more of achievement orientation with the ambition of improving their singing technique for professional purposes, whereas amateurs engaged in singing lessons as a means of self-actualization and self-expression, primarily to release emotional tensions. To summarize, the hypothesis was partly confirmed - amateurs found singing lessons more emotionally beneficial than professionals.

\section{Study III: Learning experiences and motivation in artistic development}

This study particularly addressed the overall process of skill acquisition among opera students in higher education. The present study was designed to provide data for creating a descriptive model of the process of artistic development at an opera university college. Questions regarding musical background were also included in the interviews in order to shed light on previous music experiences and formal education. Findings indicated that the majority of students had parents who appreciated musical activities such as visiting concerts or playing together. In only two cases, parents had worked professionally with music. The positive experience of playing and engaging in music activities with parents seemed to become an incitement to engage in choral singing or playing an instrument. The start of engaging in singing lessons regularly with singing teacher differed moderately between males (on average 18 years) and females (on average 20.4 years). A majority of students had prior formal musical education (on average 4.3 years) before entering the opera college. In the follow-up, more than five years after the study, five out of eight students were professionally active as opera singers.

The thematic analysis of the interview data showed that the artistic development during the time at college ( 3.5 years) comprised a broad 
learning experience. This formative process of education involved changes in competence and self-concept. The improvement of skills and change in self-concept implied a transformation of social roles. Upon entering the university, the students viewed themselves as 'talented opera students', and while by the end of their education, they could ascribe to the role of 'promising professional opera singers'. The students gave examples of major learning experiences in two areas; artistic skills and personal growth. The principal aim was to develop an appropriate singing technique. In addition to the technical skill of singing, also musical and expressive skills were involved in their vocal progress. An important learning outcome was the establishment of voice type (for example lyrical or dramatic soprano) that would enable them to select a suitable opera repertoire. Furthermore, it was important to find appropriate work methods for vocal practise and interpretation in order to work autonomously, without the reliance or support from a vocal coach or other professionals. Other means of expressiveness to master were acting skills as well as increased awareness of the context in text and music. In addition, the students described the necessity to improve their interpersonal skills; how to collaborate constructively in groups, how to communicate one's point of view and take instructions from teachers and professionals. It was also pivotal for the artistic self-concept that the students found out for themselves why excelling in opera was important to them. It appeared as if motivational factors and level of artistic skill had to be integrated in the self-concept in order to be of functional value for further progress.

The outcome of the formative process at the university college could be summarized in three variables; artistic competence (having reached a high level of artistic skills), artistic autonomy (to be able to work and make artistic decisions autonomously) and change in selfconcept (personal growth and increased self-confidence). Taken together, this study indicated that the artistic learning process involves a range of improved skills, work methods and a change in selfconcept.

This research raises questions regarding the students' experience of learning. They described their learning process as vague and quite incidental. However, the process of skill acquisition as learning for artistic development so far has not attracted researchers, possibly due 
to a conservative notion about talent. This notion of emphasising the influence of talent instead of learning on skill acquisition might also be prevalent in the artistic context and among educators. In this way, this notion contributes indirectly to a student's difficulty to grasp the learning process.

Moreover, the present study found several factors and processes in the artistic development during higher education, and simultaneously indicates the difficulties in defining and measuring constructs that change qualitatively over time.

\section{Study IV: Personality characteristics among elite students in opera and business education}

The aim of this study was to examine personality characteristics among elite students from prestigious university colleges representing two different academic settings. As noted, a number of studies point out the positive influence of conscientiousness and the negative influence of neuroticism and extraversion on traditional academic achievement. Research about the personality of artists has not studied the relationship between personality and performance outcomes. In this study, well-established measurements based on psychobiological theories of personality aspects were applied among opera and business students. A junior college sample was included and represented norm scores.

The main findings were that male opera students comprised a distinctive group, displaying significantly strikingly elevated scores in the scales of anxiety/neuroticism, extraversion and aggression compared to female opera students, female and male business students. The incidence of a high level of anxiety/neuroticism among males contradicts earlier studies showing that females generally demonstrate higher levels of emotionality. Another contrasting result was that female business students displayed an increased level of psychoticism, commonly regarded as a masculine trait. It is noteworthy that both male opera students and female business students were in the gender minority at their respective college. These indications might be interpreted in light of notions about socially constructed gender-role traits. That is, these males and females in the 
gender minority might have adapted to the norms of the gender in majority.

Another important finding was that female opera students as well as female and male business students displayed moderately elevated scores in three subscales of extraversion; notably EPQ Extraversion, IVE Impulsiveness and KSP Monotony Avoidance. The profile of extraversion indicates a disposition towards sensation seeking. In comparison, the profile of male opera singers yielded a different pattern with additionally elevated scores in extraversion. Their particular profile might suggest more of a disposition towards dysfunctional impulsivity. The male opera singers also exhibited diverting scores in non-conformity. Finally, it should also be noted that female opera students, and female and male business students scored close to norm scores in the scales of anxiety, aggression and conformity. For these three groups of students, the personality characteristics may indicate a general absence of psychic vulnerability factors.

The results would gain from being placed in a larger perspective of person-environment interactions. Change in personality is marked during young adulthood. One main influential factor is the transition from school to work life. The present study notes that certain personality aspects are more characteristic than others among elite students, but replications of the study are warranted in order to demonstrate major personality aspects in samples of high-achieving professionals in the opera and the business field. 


\section{GENERAL DISCUSSION}

In the next section, main findings and contributions of the four studies are discussed. Thereafter, shortcomings and limitations are addressed. Lastly, concluding remarks and implications for future research are presented.

\section{Major findings and contributions}

The main objectives of the present thesis were to identify specific areas of artistic development among opera singers. The body obtained in the four empirical studies suggests that the individual development of operatic artistry is a complex process where health-related issues, skill acquisition, personality characteristics and sociocultural values are crucial constituents.

One of the major findings was the marked focus on the instrument per se, the voice, for the opera singers. The results across the studies IIII indicate that the vocal functioning in singing has manifold meaning, representing a means of enabling operatic singing, a mode of artistic expression and indicators of health. In order to meet the expectations and standards set by the opera world, the opera singers need to excel in their singing technique. The singing technique was regarded as a particular and central skill for operatic artistry. It enabled the singers to sing at a high level with expressiveness and precision, and to sing satisfactorily despite adversities such as colds or performance anxiety. Although the effect of singing lessons was investigated from the perspective on well-being (Study II), the singing lessons might better be considered as a central feature in the skill acquisition process for professional singers. What was here generally labelled singing lessons is an integral part of the vocal practice behaviour for professional singers and not, as for amateur singers, a moment for self-expression and releasing emotional tensions. For professionals, the level of singing technique could be maintained and developed by practicing on one's own and by taking singing lessons 
with a vocal coach of choice. The professionals were noticeably achievement-oriented during the singing lessons. With their vocal coach, they observed any differences or changes in vocal functioning and body posture that might be affecting the singing outcome.

In addition to the singing technique as a means for operatic singing, the auditory outcome of the singing technique was also a part of the opera performance or concerts and evaluated by the audience as well as the singers themselves. How well or poorly the performance succeeded demonstrated evidence of singers' artistic qualities or expertise as reported by student and professional singers (Study I and III). The singers described the performance on stage more as an achievement in displaying their singing technique than any other expressive modes.

The performance on stage was also notably discussed from another perspective. The singers demonstrated distinct worry for possible negative criticism from significant others (Study I). A majority felt 'exposed' to the negative judgements from the audience. Although the singers refrained from recognizing this distinct and marked worry as anxiety, the diagnosis of social anxiety disorder, and in particular performance anxiety, entails this feature of persistent fear of social situations where embarrassment might occur (American Psychiatric Association, 1994).

Another aspect of the worry of not being able to meet the demands of significant others can specifically be traced in the singers' fear of 'vocal indisposition' that implied not being able to sing satisfactorily, mainly due to somatic problems such as colds and allergies. The singers would then suffer from vocal impairment and consequently not be able to perform. In addition, a range of coping strategies was demonstrated which aimed at preventing contamination or illness (Study I). The coping strategies intended to protect both the speaking and the singing voice. Another specific habit was manifested in testing the voice quality and existence. By taking a few tones, the singers assessed how well their voice functioned or if it functioned at all. Certainly, the major characteristic of opera singers is the extreme singing ability. Without this particular capacity, there is no opera singer. Vocal impairment might easily be observed by the audience and colleagues. Because the singers are soloists, they carry much responsibility of the performance outcome. However, the findings 
regarding both worry for negative criticism and fear of indisposition might be interpreted as anxieties related to not being liable to sing and its consequences. The individual might experience embarrassment and shame for incompetence and guilt for causing a poor performance. As stated earlier, high demands on musical performance can be related to work-related strain and performance anxiety.

In this specific group of opera singers, the anxiety appears to take the form of bodily preoccupation and maintenance of health with associated behaviours. From a behavioural perspective, a likely reason for the occurrence of bodily preoccupation is that the development of singing skills over the years demands an introspective stance in order to coordinate and control the body posture and functions. Bodily preoccupation is a defining characteristic of hypochondriasis and refers to an enduring attention to health- and illness-related matters (Starcevic, 2001). Increased levels of neuroticism might contribute to the negative interpretation of bodily sensations (cf. Matthews \& Gilliland, 1999). Another group of performing artists, ballet dancers also demonstrate high emotionality (Bakker, 1988, 1991), a heightened focus on their body for dance-technical reasons (Gray \& Kunkel, 2001) and hypochondrical concerns (Marchant-Haycox \& Wilson, 1992; Taylor, 1997). The dancers, like singers, use their body as their core instrument. The reported anxiety symptoms among professional opera singers show features of hypochondriasis found in relation to an overly evaluative stance of oneself (Starcevic, 1989). This speculation about similarities in symptoms is supported by links between hypochondrical concerns and anxiety disorders (Noyes, Happel, \& Yagla, 1999; Otto, Pollack, Sachs, \& Rosenbaum, 1992), and neuroticism (Ferguson, 2000; Hollifield, Tuttle, Paine, \& Kellner, 1999; Noyes, Kathol, Fisher, Philips, Suelzer, \& Woodman, 1994).

Extant inquiries on artistic or musical performance have rarely depicted artistic abilities as a form of professional expertise (see however Noice \& Noice, 2002). The conceptualization of the skill acquisition process during higher education was an attempt to create a descriptive model of actual behaviour and outcome variables from the student's point of view (Study III). The model embraced the change in social roles from being admitted to the college as 'a talented opera student' to ending the education as 'a promising professional opera singer'. The model is based on a system-oriented approach that implies 
that a system is more than the sum of its parts. The various processes of developing skills - singing technique, means of expressiveness and interpersonal skills - are highly interrelated with each other. An acquired skill in one part of the system affects other parts. The outcome variables of the opera education, here conceptualized as artistic autonomy, artistic competence and change in self-concept, illustrate the expertise required for professional operatic performance. Likewise, these three variables are considered to be interrelated with each other as well as with preceding features and processes in the learning process. Other key findings are that the skill acquisition process in higher opera education includes a broad experience of learning and skill acquisition. In addition to what is commonly attributed to artistic skills (such as musical, acting and expressive skills), the opera students stressed the importance of developing interpersonal skills specific for the opera world. For a better understanding of the complexity of skills, the example of operatic singing skills can framed as bodily-kinesthetic intelligence, a type of intelligence shared with dancers, athletes and actors (Gardner, 1983, 1993). The skill of precise muscle coordination in the vocal apparatus is similar to the control and poise that an athlete or dancer must exercise over his or her body. In acting opera, the singer need to carefully observe or imagine an action of a role figure and then carry out the action in movement, words and melody using their body as well as intellectual and emotional means. Additionally, musical intelligence draws on being able to perceive metaphorical patterns that will appear in sound. Musical intelligence is related to the perception of rhythm, melody and emotions, but the singer or musician is also able to express in a performance what he or she perceives as a musical form.

In the present empirical studies, one point of departure was that the samples of opera singers had particular talents or dispositions appropriate for the opera genre, as they had been admitted in highly selected educational settings or had already successfully settled in their opera careers. Opera students gave evidence of extensive prior musical experiences in childhood in terms of choral singing and instrumental practice, but this experience was rarely related to the opera genre (Study III). All students had been taking singing lessons from their mid or late teens, and around half of the students had been in formal 
music education before entering the opera college. These findings highlight that having prior music instruction and education might be beneficial, but insufficient in order to exercise vocal, musical and acting skills on a level that leads to being admitted to the opera college and thereafter pursuing an opera career.

The choice of approaching a highly specialized sample for investigation indicated a risk that the data would suffer from restriction of range. Instead, the results point at differences in personality characteristics among elite students at highly selected educational settings (Study IV). The findings suggested that extraversion in terms of sensation seeking was indicated as a major personality characteristic in the groups of female opera students, and female and male business students. The restless and impulsive disposition of extraversion came more in the foreground than the sociable tendency. Sensation seeking is commonly associated with high-risk sports and also dysfunctional behaviour (for a review see Roberti, 2004; Furnham, 2004). Considering the achievement-oriented nature of elite students in Study IV, it is likely that the restless and impulsive disposition is of a more functional than dysfunctional value for their educational pursuit. In spite of the fact that impulsivity and sensation-seeking are repeatedly found correlated with neurobiological measures (Zuckerman, 2003; af Klinteberg, von Knorring, \& Oreland, 2004), presumably influencing cognitive and perceptual characteristics, there seems to be a paucity of investigations on the beneficial aspects of those personality traits on the creativity process. Impulsivity might be of positive value if the individual is able to use this disposition in situations where impulsive behaviour is optimal such as acting with relatively little forethought (Dickman, 1990). This particular facet of impulsivity was found to be the most consistent among four possible facets in explaining externalizing behaviour (Miller, Flory, Lynam, \& Leukefeld, 2003). It is highly probable that the combination of the students' impulsive disposition, their particular abilities (academic, artistic), and the educational demands display a good personenvironment fit.

An interesting result was the occurrence of gender differences in personality aspects (Study IV). The findings indicated that the gender exhibiting elevated levels of neuroticism and anxiety was in the minority at respective colleges. In accordance with available evidence 
(see Costa, Terracciano, \& McCrae, 2001; Feingold, 1994), increased levels of neuroticism and anxiety are a characteristic of females, but in the present study only the females at the business college exhibited increased levels of neuroticism and anxiety. More unexpectedly, males at the opera college displayed markedly elevated levels compared to opera females. This particular result partly confirms research about high emotionality in the group of artists, but as already mentioned it refutes findings regarding general gender differences. The theoretical framework for the explanation behind why women and men differ on self-report measures of anxiety and neuroticism may be twofold. Feingold (1994) proposes the artefact model where sociocultural factors influences how women and men hold different views about the importance of possessing certain traits. These differences might differently bias the self-reports of personality. This leads to gender differences in personality inventory scores that do not reflect the underlying constructs that the inventories intend to measure. Alternatively, in line with the substance model, Egloff and Schmukle (2004) suggest that gender differences in personality inventories correctly reflect actual gender differences that the construct aims to measure. In the current study, female and male opera students might present themselves as less 'gender stereotyped' due to certain unknown sociocultural factors. However, the mixed results from the present study suggests that an explanatory framework is needed that incorporates factors of both the artefact and substance model in order to explain gender differences in elite educational settings.

The various parameters of artistic development were examined using both qualitative and quantitative measurements. The application of conducting interviews served well the exploratory stance in that all inquiries were made in-depth and in that detailed and dense descriptions could be gathered. Study I started out with interviews and followed up the results with a specially constructed questionnaire. In Study II, self-reports and interviews were chosen as a compliment to the physiological measurements, as the individual's perception and evaluation of his or her situation are regarded as paramount for deeper understanding. In Study III, the collection of interview data made it possible to place findings about skill acquisition in a certain social and temporal context. The interviews generated a vast amount of data, as there had been no predetermined constraints put on the specific 
topics. The way of classifying and formulating qualitative data into coherent concepts was important for the understanding of phenomena emerging from well-established measurements of personality characteristics (Study IV). With respect to examining the data, the possible contextual influence was regarded as additional variables both in designing the study of personality characteristics and analysing the data. The personality inventories have the obvious advantage of capturing variables more exactly. However, at the same time when variables are formulated so explicitly, there is a risk that they are too general to tap specifics of the sample or the area of concern. Quantitative data might also lose the link to the contextual influences, and the focus on variables instead of individuals is enhanced. For the pilot study (Study I), the high response rate was probably due to the fact, as some of the opera singers stated, that the specially constructed questionnaire really touched upon their experience. Taken together, future designs would benefit from using qualitative approaches with specified topics in combination with well-established questionnaires for the study of artistic development.

\section{Shortcomings and limitations}

The interest of the present thesis was to explore a range of factors and processes that was assumed to be of importance for the artistic profession and development. Thus the single denominator for the investigations was the specific sample of opera singers. However, only one out of the four studies was designed with a specific hypothesis in mind (Study IV). For the qualitative studies (Study, I, II and III), the use of retrospective and narrative accounts is of concern. Subjects might rely on memories that bias in favour of their self-concept. For the author to more thoroughly investigate certain issues in Study III, altogether three interviews were individually performed with the subjects, as this study relied on only interview data. The students provided many and varied experiences within a common thematic structure.

The external validity of the results might be questioned. The population of opera singers is small and consequently the number of subjects in the current studies was limited, in particular in Study III. However, in comparison to the population size of students and 
professional opera singers in Sweden, the sample size and response rates were relatively high across the studies. Moreover, the results of personality characteristics among opera students may not be representative for the group of professionally active opera singers (Study IV). The career paths range from freelancing nationally and internationally, as well as having permanent employment at an opera house in Sweden. Only a small number of the opera students will succeed. The career path for business students varies both in terms of work tasks and positions compared to the career path of opera singers. Therefore, additional research is needed to establish which personality characteristics would be representative for well-established opera singers and business professionals. Note also that the comparison group of business students is a convenience sample. No information could be obtained about characteristics in the total group. There is evidently a risk for selection bias. A potential effect of business students with modest levels in most personality characteristics, as in this case, might be a study sample representing norm scores in the population. Consequently, some variables of self-selection may have decreased the variation of personality characteristics.

Significant correlations were found between psychological variables relating to fear of being negatively judged and worries about the voice quality and existence (Study I). The vast interview materiel reflected distinct problems of psychological and somatic nature, yet the singers scored low on these items in the questionnaire. It was probably easier for the singers to be open about difficult issues during the interviews than while they were completing the questionnaire at home. It seems reasonable to assume that social desirability had an influence, as the singers have to rely on being a competent singer.

Professional singers appeared more emotionally detached than amateur singers during the singing lesson (Study II). A possible explanation for this difference in reported well-being might be that the range of emotional states on the VAS-scale better reflected the experiences of amateurs than professionals. The VAS-scale did not involve measures of emotional states that were associated with subjective experience of competence or successful achievement outcome. Another methodological concern is the time of testing that differed among the subjects, since the levels of stress hormones have a circadian rhythm. Additionally, the number of independent variables 
was relatively high and a number of statistical analyses were performed. The risk for mass-significance is present. Furthermore, the inclusion of subjects was limited, as it turned out that the number of older amateur subjects was very limited. It was also discovered that professional singers do not depend on taking regular singing lessons, probably due to the fact that they have already acquired a high level of singing competence and artistic autonomy.

\section{Concluding remarks and future directions}

The introduction and the empirical studies of this thesis depict diverse areas of concern for the artistic profession and development of opera singers. The empirical studies illustrate that development of artistry for opera singers can be regarded as developing an expertise with relevant skills. The expertise includes skills primarily of practical concern that relates to producing competent and professional opera performances. However, the outline of opera history shows that the artistic values for opera performances today prevail from opera works composed in the $18^{\text {th }}$ and $19^{\text {th }}$ century. This fact makes a compelling point of reference for what kind of skills are taught and how the skills are transferred by educational settings as well as for what kind of operatic expertise is appreciated by audiences around the world. To excel in the operatic genre, the individual needs to exhibit a major aptitude for the vocal expression. The prerequisite of an opera singer is the extreme vocal coordination which was stated, a critical skill to master. Singing technique was regarded as a means for high singing achievement and as an aural quality of artistic expression. The opera singer adapts to the musical and performative norms set by ancient opera works, and at the same time the opera singer seeks to express his or her individuality as an artist on stage. According to opera singers, the key to individual expression and high technical achievement appears to be found in mastering an appropriate singing technique. The question arises if there are other skills or processes that could be important and support the individual's artistic expression and achievement. The reason behind addressing this issue is that the vocal functioning is also in focus for feelings of inadequacy and illness attitudes. Taken together, the results inferred from an explorative approach adopted in the present thesis indicate that the areas of health issues, personality 
characteristics and skill acquisition process are of concern for the artistic profession and development of opera singers. The findings largely reside on empirically unbroken ground and point out several directions for future studies.

For pedagogical ends, further exploration is needed to understand the skills learned and taught in opera education. To learn how to sing or play an instrument differs importantly from attaining intellectual knowledge in that the explicit use of the body as an instrument is involved, and in that the performance situation is an evident part of the music-making for the professional. It is noteworthy that theories about artistic learning processes in higher education are lacking. However, the present results suggest that the research subject of skills and learning should include changes in self-concept and social roles, as it was shown that increased competence, that is experiences, affects the self-concept and vice versa.

For clinical purposes, it would be of value to direct research towards the aetiology of voice disorders among professional who depend on their voice. The singers explicitly demonstrate the psychological and behavioural effects of using their voice as the primary communicative mode. Firstly, proper classification and background of voice disorders are required for proper treatment. Professional voice users report change in vocal quality that might be of functional origin. Particular life events or other stressors should be studied as they relate to impairment. Secondly, it would be valuable to examine the phenomenon of vocal preoccupation with associated behaviours among opera singers. Excessive fear of indisposition and behavioural strategies to prevent vocal impairment may appear as a natural part of the lifestyle of opera singers, because they have to rely on their vocal capacity for earning their living. Nevertheless, studies might more clearly show why the fear and behaviours are persistent and also if the fear and behaviours influence practice behaviour, rehearsals and achievement outcomes - concerts and performances and the well-being of the opera singer. In this connection, the association between vocal preoccupation and personality aspects such as neuroticism/anxiety could be of interest.

Research in personality could elucidate the role of impulsivity in highly skilled and achievement-oriented individuals. With respect to current findings, it appears as if impulsivity comprises behaviours and 
processes that might have facilitating effects for elite students in their pursuit. The occurrence of impulsivity suggests a match between personality characteristics and environmental demands. This speculation is valid, because impulsivity is not a unitary trait, but is made up of multiple traits that can lead to impulsivity related behaviours but not necessarily associated with problematic actions.

From a life-span perspective, the artistic process could be illustrated from various perspectives. Artistic skills change and develop over a lifetime. As the body undergoes changes, the singer makes new experiences and the environment places new demands. It is probable that various phases - for example, the phase of entering the professional arena - involve certain skills and learning experiences that are distinct for that particular phase and that are at the same time the base for the next step. It is not known if the focus on the singing technique varies qualitatively over time and in what way a less experienced professional opera singer would differ from an experienced opera singer regarding the focus on vocal aptitude. Further research is needed to pinpoint the form of the practice behaviour over time and what constituents (social and individual aspects) are important for maintaining and developing this highly sophisticated vocal functioning.

The central questions of what constitutes artistic development factors and processes that change or promote stability over time during childhood, later education and professional life are especially suited to longitudinal research. It is important that results obtained for age-dependent phenomena or developmental phases should not be inferred to other age groups or developmental stages. The standpoint taken by the present author is that it is more important to examine phase-related features and processes than single variables that have low but consistent influence on long-term development. Moreover, the current thesis holds the view that the individual is the organizer of events inside and outside him- or herself, and that there is an ongoing interaction between exterior events, physiology and psyche. These components cannot be separated (cf. Magnusson, 1999). In addition, our experiences form the basis for additional experience and knowledge. Furthermore, our emotions and thoughts regarding the future have an impact of the current state of mind and life situation. The empirical studies in the thesis are evidence of this particular 
complexity that arises when research focuses on learning and individual development. Research variables are necessarily a reduction of occurring phenomena, yet they are vital for exploring central components and underlying processes of development. 


\section{REFERENCES}

American Psychiatric Association (1994). Diagnostic and statistical manual of mental disorders ( $4^{\text {th }}$ ed.). Washington, DC: American Psychiatric Association.

Andersson, K., \& Schalén, L. (1998). Etiology and treatment of psychogenic voice disorders: Results of a follow-up study of thirty patients. Journal of Voice, 12, 96-106.

Aronson, A. (1990). Clinical voice disorders: An interdisciplinary approach ( ${ }^{\text {rd }}$ ed.). New York: Thieme.

Bakker, F.C. (1988). Personality differences between young dancers and nondancers. Personality and Individual Differences, 9, 121-131.

Bakker, F.C. (1991). Development of personality in dancers: A longitudinal study. Personality and Individual Differences, 12, 671-681.

Barratt, E.S. (1965). Factor analysis of some psychometric measures of impulsiveness and anxiety. Psychological Reports, 16, 547-554.

Barrick, M.R., \& Mount, M.K. (1991). The Big Five personality dimensions and job performance: A meta-analysis. Personnel Psychology, 44, 1-26.

Barrick, M.R., Mount, M.K., \& Gupta, R. (2003). Meta-analysis of the relationship between the five-factor model of personality and Holland's occupational types. Personnel Psychology, 56, 45-74.

Bateson, P. (1996). Design for a life. In D. Magnusson (Ed.), The lifespan development of individuals: Behavioural, neurobiological, and psychosocial perspectives. A synthesis (pp. 1-20). Cambridge: Cambridge University Press.

Bergman, H., \& Schalling, D. (1981). The influence of age and sex on the KSP personality scales. Unpublished manuscript, Department of Psychiatry and Psychology, Karolinska Institute, Stockholm, Sweden.

Björling, J. (1994). Med bagaget $i$ strupen [With the luggage in the throat]. Stockholm: Wahlström \& Widstrand.

Brandfonbrenner, A.G., \& Kjelland, J.M. (2002). Music medicine. In R. Parncutt \& G.E. McPherson (Eds.), The science \& psychology of music performance: Creative strategies for teaching and learning (pp. 83-96). Oxford: Oxford University Press.

Burland, K., \& Davidson, J.W. (2002). Training the talented. Music Education Research, 4, 121-140.

Celletti, R. (1991). A bistory of bel canto. Oxford: Clarendon Press.

Chesky K., \& Henoch, M.A. (2000). Instrument-specific reports of hearing loss: Differences between classical and nonclassical musicians. Medical Problems of Performing Artists, 15, 35-38.

Clarke, E.F., \& Davidson, J.W. (1998). The body in performance. In W. Thomas (Ed.), Composition-performance-reception. Studies in the creative process of music (pp. 74-92). Aldershot: Ashgate.

Clark, \& Watson (1999). Temperament. A new paradigm for trait psychology. In L.A. Pervin \& O.P. John (Eds.), Handbook of personality. Theory and research $\left(2^{\text {nd }}\right.$ ed.) (pp. 399-423). New York: The Guilford Press. 
Clift, S.M., \& Hancox, G. (2001). The perceived benefits of singing: Findings from preliminary surveys of a university college choral society. The Journal of The Royal Society for the Promotion of Health, 121, 248-256.

Cloninger, C.R., Svrakic, D.M., \& Pszybeck, T.R. (1993). A psychobiological model of temperament and character. Archives of General Psychiatry, 50, 975-990.

Colley, A., Roberts, N., \& Chipps, A. (1985). Sex-role identity, personality, and participation in team and individual sports by males and females. International Journal of Sport Psychology, 16, 103-112.

Cook, N. (2000). Music. A very short introduction. Oxford: Oxford University Press.

Cooper, C.L., \& Wills, G.I.D. (1988). Pressure sensitive. Popular musicians under stress. London: Sage Publications.

Costa, P.T. Jr., \& McCrae, (1992). Four ways five factors are not basic. Personality and Individual Differences, 13, 861-865.

Costa, P.T., Terracciano, A., \& McCrae, R.R. (2001). Gender differences in personality traits across cultures: Robust and surprising findings. Journal of Personality and Social Psychology, 81, 322-331.

Davidson, J.W. (2001). The role of the body in the production and perception of solo vocal performance: A case study of Annie Lennox. Musicae Scientiae, 2, 235-256.

Davidson, J.W., \& Coimbra, D.C. (2001). Investigating performance evaluation by assessors of singers in a music college setting. Musicae Scientae, 1, 33-53.

Davies, A. (1981). The Hellenism of early Italian opera. In J. Redmond (Ed.), Drama, dance and music (pp. 31-46). Cambridge: Cambridge University Press.

Davis, C., Fox, J., Brewer, H., \& Ratusny, D. (1995). Motivations to exercise as a function of personality characteristics, age and gender. Personality and Individual Differences, 19, 165-174.

De Fruyt, F., \& Mervielde, I. (1999). RIASEC types and big five traits as predictors of employment status and nature of employment. Personnel Psychology, 52, 701-727.

Dews, C.B., \& Williams, M.S. (1989). Student musicians' personality styles, stresses, and coping patterns. Psychology of Music, 17, 37-47.

Dickman S.J. (1990). Functional and dysfunctional impulsivity: Personality and cognitive correlates. Journal of Personality and Social Psychology, 58, 95-102.

Digman, J.M. (1990). Personality structure: Emergence of the five-factor model. Annual Review of Psychology, 41, 417-440.

Donington, R. (1981). The rise of opera. London: Faber and Faber.

Dowd, R., \& Innes, J.M. (1981). Sport and personality: Effects of type of sport and level of competition. Perceptual and Motor Skills, 53, 79-89.

Drake, C., \& Palmer, C. (2000). Skill acquisition in music performance: Relations between planning and temporal control. Cognition, 74, 1-32.

Dudek, S.Z., Bernèche, R., Bérubé, H., \& Royer, S. (1991). Personality determinants of the commitment to the profession of art. Creativity Research Journal, 4, 367-389. 
Egan, S., \& Stelmack, R.M. (2003). A personality profile of Mount Everest climbers. Personality and Individual Differences, 34, 1491-1494.

Egloff, B., \& Gruhn, A.J. (1996). Personality and endurance sports. Personality and Individual Differences, 21, 223-229.

Egloff, B., \& Schmukle, S.C. (2004). Gender differences in implicit and explicit anxiety measures. Personality and Individual Differences, 36, 1807-1815.

Ericsson, K.A. (1997). Deliberate practice and the acquisition of expert performance: An overview. In H. Jørgensen \& A.C. Lehmann (Eds.), Does practice make perfect? Current theory and research on instrumental music practice (pp. 7-51). MNH-publikasjoner 1997:1. Oslo: Norges musikkhøgskole.

Ericsson, K.A., Krampe, R.T., \& Tesch-Römer, C. (1993). The role of deliberate practice and the acquisition of expert performance. Psychological Review, 100, 363-406.

Eysenck, H.J. (1967). The biological bases of personality. Baltimore, MD: University Park Press.

Eysenck, H.J., \& Eysenck, S.B.G. (1975). Manual of the Eysenck Personality Questionnaire. London: Hodder \& Stoughton.

Eysenck, S.B., \& Eysenck, H.J. (1977). The place of impulsiveness in a dimensional system of personality description. British Journal of Social and Clinical Psychology, 16, 57-68.

Eysenck, H.J., \& Eysenck, S.B. (1978). Impulsiveness and venturesomeness: Their position in a dimensional system of personality description. Psychological Reports, 43, 1247-1255.

Eysenck, H.J., \& Eysenck, M.W. (1985). Personality and individual differences: $A$ natural science approach. New York: Plenum.

Eysenck, H.J., Nias, D.K.B., \& Cox, D.N. (1982). Sport and personality. Advances in Behavior Research and Therapy, 4, 1-56.

Fahrenberg, J. (1987). Concepts of activation and arousal in the theory of emotionality (neuroticism). In J. Strelau \& H.J. Eysenck (Eds.), Personality dimensions and arousal (pp. 99-120). New York: Plenum Press.

Feingold, A. (1994). Gender differences in personality: A meta-analysis. Psychological Bulletin, 116, 429-456.

Feist, G.J. (1998). A meta-analysis of personality in scientific and artistic creativity. Personality and Social Psychology Review, 2, 290-309.

Feist, G.J. (1999). The influence of personality on artistic and scientific creativity. In R.J. Sternberg (Ed.), Handbook of creativity (pp. 273-296). Cambridge: Cambridge University Press.

Ferguson, E. (2000). Hypochondrical concerns and the five factor model of personality. Journal of Personality, 68, 705-724.

Franzén, N.O. (1982). Jenny Lind. En biografi [Jenny Lind. A biography]. Stockholm: Bonniers.

Furnham, A. (2004). Personality and leisure activities: Sensation seeking and spare-time activities. In R.M. Stelmack (Ed.), On psychobiology of personality. Essays in honor of Marvin Zuckerman (pp. 167-183). Oxford: Elsevier Ltd. 
Gabbard, G.O. (2000). Psychodynamic psychiatry in clinical practice (3 ${ }^{\text {rd }}$ ed.). Washington, DC: American Psychiatry Press.

Gardner, H. (1973). The arts and human development: A psychological study of the artistic process. New York: Wiley.

Gardner, H. (1983). Frames of mind: The theory of multiple intelligences. New York: BasicBooks.

Gardner, H. (1993). Multiple intelligences: The theory in practice. New York: BasicBooks.

Ginsbourg, J. (2002). Classical singers learning and memorising a new song: An observational study. Psychology of Music, 30, 58-101.

Gomà-i-Freixanet, M. (1995). Prosoical and antisocial aspects of personality. Personality and Individual Differences, 19, 125-134.

Gomà-i-Freixanet, M. (2004). Sensation seeking and participation in physical risk sports. In R.M. Stelmack (Ed.), On psychobiology of personality. Essays in honor of Marvin Zuckerman, (pp. 185-201). Oxford: Elsevier Ltd.

Götz, K.O., \& Götz, K. (1979a). Personality characteristics of professional artists. Perceptual and Motor Skills, 49, 327-334.

Götz, K.O., \& Götz, K. (1979b). Personality characteristics of successful artists. Perceptual and Motor Skills, 49, 919-924.

Gray, J.A. (1982). The neuropsychology of anxiety: An enquiry into the functions of the septo-hippocampal system. Oxford: Clarendon Press.

Gray, K.M., \& Kunkel, M.A. (2001). The experience of female ballet dancers: A grounded theory. High Ability Studies, 12, 7-25.

Grout, D.J. (1965). A short history of opera (2 ${ }^{\text {nd }}$ ed.). New York: Columbia University Press.

Hallam, S. (1997). What do we know about practising? Towards a model synthesising the research literature. In. H. Jørgensen, \& A. Lehmann (Eds.), Does practice make perfect? Current theory and research on instrumental music practice (pp. 179-231 ). MNH-publikasjoner 1997:1. Oslo: Norges musikkhøgskole.

Hallam, S. (2001). The development of metacognition in musicians: Implications for education. British Journal of Music Education, 18, 27-39.

Hallam, S. (2002). Constructions of musical ability. Bulletin of the Council for Research in Music Education, 153, 102-108.

Hamilton, L.H., Kella, J.J., \& Hamilton, W.G. (1995). Personality and occupational stress in elite performers. Medical Problems of Performing Artists, 10, 89-99.

Hammond, J., \& Edelmann, R.J. (1991). The act of being: Personality characteristics of professional actors, amateur actors and non-actors. In G. Wilson (Ed.), Psychology and performing arts (pp. 123-131). Amsterdam: Swets \& Zeitlinger.

Hansen, E.B., \& Breivik, G. (2001). Sensation seeking as a predictor of positive and negative risk behaviour among adolescents. Personality and Individual Differences, 30, 627-640. 
Hogan, R., \& Blake, R. (1999). John Holland's vocational typology and personality theory. Journal of Vocational Behavior, 55, 41-56.

Hogikyan, N.D., Appel, S., Guinn, L.W., \& Haxer, M.J. (1999). Vocal folds nodules in adult singers: Regional opinions about etiologic factors, career impact and treatment. A survey of otolaryngologists, speech pathologists, and teachers of singing. Journal of Voice, 13, 128-142.

Holland, J.L. (1997). Making vocational choices. A theory of vocational personalities and work environments. Odessa: Psychological Assessment Resources, Inc.

Hollifield, M., Tuttle, L., Paine, S., \& Kellner, R. (1999). Hypochondriasis and somatization related to personality and attitudes towards self. Psychosomatics, 40, 387-395.

Horowitz, F.D., \& O’Brien, M. (1985). The gifted and talented. Developmental perspectives. Washington: American Psychological Association.

House, A.O., \& Andrews, H.B. (1987). Life events and difficulties preceding the onset of functional dysphonia. Journal of Psychosomatic Research, 32, 311-319.

Howe, M.J.A., Davidson, J.W., Moore, D.G., \& Sloboda, J.A. (1995). Are there early childhood signs of musical ability. Psychology of Music, 23, 162-176.

Howe, M.J.A., Davidson, J.W., \& Sloboda, J.A. (1998). Innate talents: Reality of myth? Behavioral and Brain Sciences, 21, 399-442.

Howe, M.J.A., \& Sloboda, J.A. (1991). Young musicians' accounts of significant influences in their early lives. 1. The family and the musica background. British Journal of Music Education, 8, 39-52.

Hu, C., \& Gong, Y. (1990). Personality differences between writers and mathematicians on the EPQ. Personality and Individual Differences, 11, 637-638.

Jack, S.J., \& Ronan, K.R. (1998). Sensation seeking among high- and low-risk sports participants. Personality and Individual Differences, 25, 1063-1083.

Jamison, K.R. (1993). Touched with fire: Manic-depression illness and the artistic temperament. New York: Free Press.

Jones, G., \& Swain, A. (1992). Intensity and direction as dimensions of competitive state anxiety and relationships with competitiveness. Perceptual and Motor Skills, 74, 467-472.

Jørgensen, H. (2002). Instrumental performance expertise and amount of practice among instrumental students in a conservatoire. Music Education Research, 4, 105-119.

Judge, T.A., Heller, D., \& Mount, M.K. (2002). Five-factor model of personality and job satisfaction: A meta-analysis. Journal of Applied Psychology, 87, 530-541.

Juslin, P.H., \& Laukka, P. (2003). Communication of emotions in vocal expression and music performance: Different channels, same code? Psychological Bulletin, 129, 770-814.

Kähäri, K.R. (2002). The influence of music on hearing: A study of classical and rock/jazz musicians. Gothenburg: Department of Otolaryngology, Gothenburg University.

Kemp, A.E. (1996). The musical temperament: Psychology and personality of musicians. Oxford: Oxford University Press. 
Kenny, D.T., Davis, P., \& Oates, J. (2004). Music performance anxiety and occupational stress amongst opera chorus artists and their relationship with state and trait anxiety and perfectionism. Anxiety Disorders, 18, 757-777.

Kimbell, D. (1991). Italian opera. Cambridge: Cambridge University Press.

Kirkcaldy B.D. (1982). Personality profiles of at various levels of athletic participation. Personality and Individual Differences, 3, 321-326.

Kirkcaldy, B.D., \& Furnham, A. (1991). Extraversion, neuroticism, psychoticism and recreational choice. Personality and Individual Differences, 12, 737-745.

Kirnarskaya, D., \& Winner, E. (1997). Musical ability in a new key: Exploring the expressive ear for music. Psychomusicology, 16, 2-16.

af Klinteberg, B., Andersson, T., Magnusson, D., \& Stattin, H. (1993). Hyperactive behaviour in childhood as related to subsequent alcohol problems and violent offending: A longitudinal study of male subjects. Personality and Individual Differences, 15, 381-388.

af Klinteberg, B., von Knorring, L., \& Oreland, L. (2004). On the psychobiology of impulsivity. In R. Stelmack (Ed.). On the psychobiology of personality: Essays in Honor of Marvin Zuckerman (pp. 429-451). New York: Elsevier Science.

Kopiez, R. (1997). "Singers are late beginners": Sängerbiographien aus Sicht der Expertise-forschung. Eine Schwachstellenanalyse sängerischer AusbildungsVerläufe. [Singer biographies from the perspective of expertise research. An analysis of critical points in singing education]. In H. Gembris, R.-D. Kraemer, \& G. Maas (Eds.), Musikpädagogische Forschungsberichte 1996 (pp. 37-56). Augsburg: Wissner.

von Knorring, L., Oreland, L., \& Winblad, B. (1984). Personality traits related to monoamine oxidase activity in platelets. Psychiatry Research, 12, 11-26.

Larson, L.M., Rottinghaus, P.J., \& Borgen, F.H. (2002). Meta-analyses of big six interests and big five personality factors. Journal of Vocational Behavior, 61, 217-239.

Levander, M. (1988). Neuropsychology of handedness. Unpublished doctoral dissertation. Department of Psychology, Stockholm University, Sweden.

Lindenberger, H. (1984). Opera. The extravagant art. Ithaca: Cornell University Press.

Littlejohn, D. (1992). The ultimate art. Essays around and about opera. Berkeley: University of California Press.

Ludwig, A.M. (1995). The price of greatness. Resolving the creativity and madness controversy. New York: The Guilford Press.

Lundh, L-G., Berg, B., Johansson, H., Nilsson, L.K., Sandberg, J., \& Segerstedt, A. (2002). Social anxiety is associated with a negatively distorted perception of one's own voice. Cognitive Behaviour Therapy, 31, 25-30.

Luterkort, I. (1998). Om igen, herr Molander! Kungl. Dramatiska Teaterns elevskola 1787-1964. [Once again, mr. Molander! The school at the Royal Dramatic Theatre]. Stockholm: Stockholmia Förlag.

Lynn, R., \& Martin, T. (1997). Gender differences in extraversion, neuroticism, and psychoticism in 37 nations. Journal of Social Psychology, 137, 369-373. 
Magnusson, D. (1999). Holistic interactionism: A perspective for research on personality development. In L.A. Pervin \& O.P. John (Eds.), Handbook of personality. Theory and research ( $2^{\text {nd }}$ ed.) (pp. 219-247). New York: The Guilford Press.

Manturzewska. M. (1990). A biographical study of the life-span development of professional musicians. Psychology of Music, 18, 112-139.

Marchant-Haycox, S.E., \& Wilson, G.D. (1992). Personality and stress in performing artists. Personality and Individual Differences, 13, 1061-1068.

Mark, M.L., \& Gary, C.L. (1992). A history of American music education. New York: Schirmer Books.

Martorella, R. (1982). The sociology of opera. New York: Praeger Publishers.

Matthews, G. (2004). Neuroticism from the top down: Psychophysiology and negative emotionality. In R.M. Stelmack (Ed.), On psychobiology of personality. Essays in honor of Marvin Zuckerman (pp. 249-266). Oxford: Elsevier Ltd.

Matthews, G., \& Gilliland, K. (1999). The personality theories of H.J. Eysenck and J.A. Gray: A comparative review. Personality and Individual Differences, 26, 583-626.

Maynard, I.W., Hemmings, B., \& Warwick-Evans, L. (1995). The effects of somatic intervention strategy on competitive state anxiety and performance in semi-professional soccer players. The Sport Psychologist, 9, 51-64.

Mendoza, E., \& Carballo, G. (1999). Vocal tremor and psychological stress. Journal of Voice, 13, 105-112.

Middlestadt, S.E., \& Fishbein, M. (1988). Health and occupational correlates of perceived occupational stress in symphony orchestra musicians. Journal of Occupational Medicine, 3, 687-692.

Miller, J., Flory, K., Lynam, D., \& Leukefeld, C. (2003). A test of the four-factor model of impulsivity-related traits. Personality and Individual Differences, 34, 1403-1418.

Milutinovic, Z. (1996). Classification of voice pathology. Folia Phoniatrica Logopaedica, 48, 301-308.

Mohan, J., \& Tiwana, M. (1987). Personality and alienation of creative writers: A brief report. Personality and Individual Differences, 8, 449.

Moore, D.G., Burland, K., Davidson, J.W. (2003). The social context of musical success: A developmental account. British Journal of Psychology, 94, 529-549.

Mor, S., Day, H.I., Flett, G.L., \& Hewitt, P.L. (1995). Perfectionism, control, and components of performance anxiety in professional artists. Cognitive Therapy and Research, 19, 207-225.

Morales, O., \& Norlind, T. (1921). Kungl. Musikaliska Akademien 1771-1921. Minnesskrift [The Royal Music Academy 1771-1921. Memorial publication]. Stockholm: Bröderna Lagerströms förlag.

Morrison, M.D., \& Rammage, L.A. (1993). Muscle misuse voice disorders: Description and classification. Acta Otolaryngologica, 113, 428-434. 
Newcombe, P.A., \& Boyle, G.J. (1995). High school students' sports personalities: Variations across participation level, gender, type of sport, and success. International Journal of Sport Psychology, 26, 277-294.

Nielsen, S. G. (2004). Strategies and self-efficacy beliefs in instrumental and vocal individual practice: A study of students in higher music education. Psychology of Music, 32, 418-431.

Noice, T., \& Noice, H. (2002). The expertise of professional actors: A review of recent research. High Ability Studies, 13, 7-19.

Noyes, R., Happel, A.J., \& Yagla, S.J. (1999). Correlates of hypochondriasis in a nonclinical population. Psychosomatics: Journal of Consultation Liaison Psychiatry, 40, 461-469.

Noyes, R., Jr., Kathol, R.G., Fisher, M.M., Philips, B.M., Suelzer, M.T., \& Woodman, C.L. (1994). Psychiatric comorbidity among patients with hypochondriasis. General Hospital Psychiatry, 16, 78-87.

O’Neill, S.A., \& McPerson, G.E. (2002). Motivation. In R. Parncutt \& G.E. McPherson (Eds.), The science \& psychology of music performance: Creative strategies for teaching and learning (p. 31-46). Oxford: Oxford University Press.

Operahögskolan (2005). Retrieved February 27, 2005 from Operahögskolan Stockholm [University college of opera Stockholm] Web site: http://www.operahogskolan.se

Orrey, L. (1987). Opera. A concise history. London: Thames and Hudson.

Ostwald, P. (1992). Psychodynamics of musicians. Medical Problems of Performing Artists, 7, 110-113.

Ostwald, P., Avery, M., \& Ostwald, L.D. (1998). Psychiatric problems of performing artists. In R.T. Sataloff, A.G. Brandfonbrenner, \& R.J. Ledermann (Eds.), Performing arts medicine ( $2^{\text {nd }}$ ed.) (pp. 337-348). San Diego: Singular Publishing Group, Inc.

Otto, M.W., Pollack, M.H., Sachs, G.S., \& Rosenbaum, J.F. (1992). Hypochondrical concerns, anxiety sensitivity, and panic disorder. Journal of Anxiety Disorders, 6, 93-104.

Patton, M.Q. (1987). How to use qualitative methods in evaluation. London: Sage Publications.

Pettersen, V., \& Westgaard, R.H. (2004). Muscle activity in professional classical singing: A study on muscles in the shoulder, neck and trunk. Logopedics Phoniatrics Vocology, 29, 56-65.

Phyland, D.J., Oates, J., \& Greenwood, K.M. (1999). Self-reported voice problems among three groups of professional singers. Journal of Voice, 13, 602-611.

Post, F. (1994). Creativity and psychopathology. A study of 291 world-famous men. British Journal of Psychiatry, 165, 22-34.

Pruett, K.D. (1989). Music of the self and others: Longitudinal observations on musical giftedness. The Psychoanalytic Study of the Child, 44, 87-100.

Raeburn, S.D. (1999). Psychological issues and treatment strategies in popular musicians: A review, Part 1. Medical Problems of Performing Artists, 14, 171-179. 
Raeburn, S.D. (2000). Psychological issues and treatment strategies in popular musicians: A review, Part 2. Medical Problems of Performing Artists, 15, 6-16.

Roberti, J.W. (2004). A review of behavioural and biological correlates of sensation seeking. Journal of Research in Personality, 38, 256-279.

Rosen, D.C., Heuer, R.J., \& Sataloff, R.T. (1998). Psychological aspects of voice disorders. In R.T. Sataloff, A.G. Brandfonbrenner, \& R.J. Ledermann (Eds.), Performing arts medicine (2 ${ }^{\text {nd }}$ ed.) (pp. 369-398). San Diego: Singular Publishing Group, Inc.

Rosen, C.A., \& Murry, T. (2000). Voice handicap index in singers. Journal of Voice, 14, 370-377.

Rosselli, J. (2000). Song into theatre: The beginnings of opera. In J. Potter (Ed.), The Cambridge companion to singing (pp. 83-95). Cambridge: Cambridge University Press.

Royal Swedish Academy of Music (1991). Gustavian opera. Swedish opera, dance and theatre 1771-1809. Stockholm: Royal Swedish Academy of Music.

Sadie, S. (Ed.) (1989). History of opera. London: Macmillan Press Ltd.

Sadie, S. (Ed.) (1992). The new Grove dictionary of opera (2 ${ }^{\text {nd }}$ ed., Vols. 1-4). London: Macmillan Press Ltd.

Salgado, J.F. (1997). The five factor model of personality and job performance in the European Community. Journal of Applied Psychology, 82, 30-43.

Sapir, S., Mathers-Schmidt, B., \& Larson, G.W. (1996). Singers' and non-singers' vocal health, vocal behaviours, and attitudes towards voice and singing: Indirect findings from a questionnaire. European Journal of Disorders of Communication, 31, 193-209.

Sataloff, R.T. (1998). Care of the professional voice. In R.T. Sataloff, A.G. Brandfonbrenner, \& R.J. Ledermann (Eds.), Performing arts medicine (2 ${ }^{\text {nd }}$ ed.) (pp. 137-187). San Diego: Singular Publishing Group, Inc.

Saulsman, L.M., \& Page, A.C. (2004). The five-factor model and personality disorder empirical literature: A meta-analytic review. Clinical Psychology Review, 23, 1055-1085.

Schalling, D. (1978). Psychopathy-related personality variables and the psychophysiology of socialization. In R.D. Hare \& D. Schalling (Eds.), Psychopathic behavior: Approaches to research (pp. 85-106). Chichester: Wiley.

Schalling, D. (1993). Neurochemical correlates of personality, impulsivity and disinhibitory suicidality. In S. Hodgins (Ed.), Mental disorder and crime (pp. 208-226). Newbury Park, CA: Sage.

Schalling, D., Åsberg, M., Edman, G., \& Oreland, L. (1987). Markers for vulnerability to psychopathology: Temperament traits associated with platelet MAO activity. Acta Psychiatrica Scandinavia, 76, 172-182.

Schalling, D., Edman, G., \& Åsberg, M. (1983). Impulsive cognitive style and inability to tolerate boredom: psychobiological studies of temperamental vulnerability. In M. Zuckerman (Ed.), Biological bases for sensation seeking, impulsivity, and anxiety (pp. 123-145). Erlbaum: Hillsdale, NJ. 
Shuter-Dyson, R. (1999). In D. Deutsch (Ed.), The psychology of music (2 ${ }^{\text {nd }}$ ed.) (pp. 627-651). San Diego: Academic Press.

Simon, J.A., \& Chase, W.G. (1973). Skill in chess. American Scientist, 61, 394-403.

Simonton, D.K. (1999). Creativity and genius. In L.A. Pervin \& O.P. John (Eds.), Handbook of personality. Theory and research (2 ${ }^{\text {nd }}$ ed.) (pp. 629-652). New York: The Guilford Press.

Skuncke, M.-C., \& Ivarsdotter, A. (1998). Svenska operans födelse. Studier $i$ gustaviansk musikdramatik [The birth of the Swedish opera. Studies in Gustavian music drama]. Eskilstuna: Atlantis.

Sloboda, J.A., \& Howe, M.J.A. (1991). Biographical precursors of musical excellence: An interview study. Psychology of Music, 19, 3-21.

Sloboda, J.A., Davidson, J.W., \& Howe, M.J.A. (1994). Is everyone musical? Psychologist, 7, 349-355.

Sloboda, J.A., Davidson, J.W., Howe, M.J.A., \& Moore, D.G. (1996). The role of practice in the development of performing musicians. British Journal of Psychology, 87, 287-309.

Sohlmans musiklexikon [Sohlmans music dictionary] (1975). Stockholm: Sohlmans förlag AB.

Sørensen, I. (1993). Operalexikonet [The opera dictionary]. Stockholm: Forum.

Sosniak, L.A. (1985). Learning to be a concert pianist. In B.S. Bloom (Ed.), Developing talent in young people (pp. 19-67). New York: Ballantine Books.

Spielberger, C.D., Gorsuch, R.L., \& Lushene, R.E. (1979). STAI manual for the state-trait anxiety questionniare ("Self-evaluation questionnaire"). Consulting Psychologists Press, Inc.: Palo Alto.

Spielberger, C.D., Ritterband, L.M., Sydeman, S.J., Reheiser, E.C., \& Unger, K.K. (1995). Assessment of emotional state and personality traits: Measuring psychological vital signs. In J.M. Butcher (Ed.), Clinical personality assessment: Practical approaches (pp. 42-58). New York: Oxford University Press.

Starcevic, V. (1989). Contrasting patterns in the relationship between hypochondriasis and narcissism. British Journal of Medical Psychology, 62, $311-323$.

Starcevic, V. (2001). Clinical features and diagnosis of hypochondriasis. In V. Starcevic \& D.R. Lipsitt (Eds.), Hypochondriasis. Modern perspectives on an ancient malady (pp. 21-59). Oxford: Oxford University Press.

Stark, J. (1999). Bel canto: A history of vocal pedagogy. Toronto: University of Toronto Press.

Stelmack, R.M. (Ed.) (2004a). On psychobiology of personality. Essays in honor of Marvin Zuckerman. Oxford: Elsevier Ltd.

Stelmack, R.M. (2004b). On personality and arousal: A historical perspective on Eysenck and Zuckerman. In R.M. Stelmack (Ed.), On psychobiology of personality. Essays in honor of Marvin Zuckerman (pp. 17-28). Oxford: Elsevier Ltd. 
Steptoe, A. (2001). Negative emotions in music performance: A review and a theoretical framework. In P.N. Juslin \& J.A. Sloboda (Eds.), Music and emotion. Theory and research (pp. 291-307). Oxford: Oxford University Press.

Steptoe, A., \& Fidler, H. (1987). Stage fright in orchestral musicians: A study of cognitive and behavioural strategies in performance anxiety. British Journal of Psychology, 78, 241-249.

Sternberg, R.J. (1996). Costs of expertise. In A.K. Ericsson (Ed.), The road to excellence. The acquisition of expert performance in the arts and sciences, sports and games (pp. 347-354). New Jersey: Lawrence Erlbaum Associates.

Sternberg, R.J., \& Davidson, J.E. (1986). Conceptions of giftedness. Cambridge: Cambridge University Press.

Strauss, A., \& Corbin, J. (1990). Basics of qualitative research: Grounded theory procedures and techniques. Newbury Park, CA: Sage.

Sundberg, J., Niska Thörnvik, M., \& Söderström, A.M. (1998). Age and voice quality in professional singers. Logopedics Phoniatrics Vocology, 23, 169-176.

Tannenbaum, A.J. (1986). Giftedness: A psychosocial approach. In R.J. Sternberg \& J.E. Davidson (Eds.), Conceptions of giftedness (pp. 21-53). Cambridge: Cambridge University Press.

Taylor, L.D. (1997). MMPI-2 and ballet majors. Personality and Individual Differences, 22, 521-526.

Teachout, D.J. (2001). The relationship between personality and the teaching effectiveness of music student teachers. Psychology of Music, 29, 179-192.

Tellegen, A. (1985). Structures of mood and personality and their relevance to assessing anxiety, with an emphasis on self-report. In A.H. Tuma \& J.D. Maser (Eds.), Anxiety and the anxiety disorders (pp. 681-706). Hillsdale, NJ: Erlbaum.

Tepe, E.S., Deutsch, E.S., Sampson, Q., Lawless, S., Reilly, J.S., \& Sataloff, R.T. (2002). A pilot survey of vocal health in young singers. Journal of Voice, 16, 244-250.

Tett, R.P., Jackson, D.N., \& Rothstein, M. (1991). Personality measures as predictors of job performance: A meta-analytic review. Personnel Psychology, 44, 703-742.

Theorell, T., Alberg-Hultén, G., Sigala, F., Perski, A., Söderholm, M., Callner, A., \& Eneroth, P. (1990). A psychosocial and biomedical comparison between men in six contrasting service occupations. Work, and Stress, 4, 51-63.

Thomasson, M., \& Sundberg, J. (1999). Consistency of phonatory breathing patterns in professional operatic singers. Journal of Voice, 13, 529-541.

Tokar, D.M., Fischer, A.R., \& Subich, L.M. (1998). Personality and vocational behaviour: A selective review of the literature, 1993-1997. Journal of Vocational Behavior, 53, 115-153.

van Kemenade, J.F.L.M., van Son, M.J.M., \& van Heesch, N.C.A. (1995). Performance anxiety among professional musicians in symphonic orchestras: A self-report study. Psychological Report, 77, 555-562. 
Vurma, A., \& Ross, J. (2000). Priorities in voice training: Carrying power or tone quality. Musicae Scientiae, 4, 75-93.

Watson, D., \& Clark, L.A. (1993). Behavioral disinhibition versus constraint: A dispositional perspective. In D.M. Wegner \& J.W. Pennebaker (Eds.), Handbook of mental control (pp. 506-527). Upper Saddle River, MJ: Prentice Hall.

Welch, G.F., \& Sundberg, J. (2002). Solo voice. In R. Parncutt \& G.E. McPherson (Eds.), The science \& psychology of music performance: Creative strategies for teaching and learning (pp. 253-268). Oxford: Oxford University Press.

Wesner, R.B., Noyes, R.Jr., \& Davis, T.L. (1990). The occurrence of performance anxiety among musicians. Journal of Affective Disorders, 18, 177-185.

Williamon, A., \& Valentine, E. (2000). Quantity and quality of musical practice as predictors of performance quality. British Journal of Psychology, 91, 353-37.

Wilson, G.D. (2001). Psychology for performing artists ( ${ }^{\text {nd }}$ ed.). London: Whurr.

Wilson, G.D., \& Roland, D. (2002). Performance anxiety. In R. Parncutt \& G.E. McPherson (Eds.), The science \& psychology of music performance: Creative strategies for teaching and learning (pp. 47-61). Oxford: Oxford University Press.

Winner, E. (2000). The origins and ends of giftedness. American Psychologist, 55, 159-169.

Winner, E., \& Martino, G. (2000). Giftedness in non-academic domains: The case of the visual arts and music. In K.A. Heller, F.J. Mönks, R.J. Sternberg, \&, R.F. Subotnik (Eds.), International handbook of giftedness and talent ( $2^{\text {nd }} \mathrm{ed}$.) (pp. 95-110). Amsterdam: Elsevier.

Winter, D.G., John, O.P., Stewart, A.J., Klohnen, E.C., \& Duncan, L.E. (1998). Traits and motives: Toward an integration of two traditions in personality research. Psychological Review, 105, 230-250.

Zaza, C., Charles, C., \& Muszynski, A. (1998). The meaning of playing-related musculoskeletal disorders to classic musicians. Social Science Medicine, 47, 2013-2023.

Zuckerman, M. (1979). Sensation seeking: Beyond the optimal level of arousal. Hillsdale, NJ: Erlbaum.

Zuckerman, M. (1983). Sensation seeking and sports. Personality and Individual Differences, 4, 285-293.

Zuckerman, M. (1994). Behavioral expressions and biosocial bases of sensation seeking. New York, NY: Cambridge University Press.

Zuckerman, M. (1999). Vulnerability to psychopathology: A biosocial model. Washington: American Psychological Association.

Zuckerman, M. (2003). Biological bases of personality. In T. Millon and M.J. Lerner (Eds.). Handbook of psychology (pp. 85-116). New York: Wiley.

Zuckerman, M., Eysenck, S., \& Eysenck, H.J. (1978). Sensation seeking in England and America: Cross cultural, age and sex comparisons. Journal of Consulting and Clinical Psychology, 46, 139-149. 
Zuckerman, M., Kuhlman, D.M., \& Camac, C.C. (1988). What lies beyond E and $\mathrm{N}$ ? Factor analyses of scales believed to measure basic dimensions of personality. Journal of Personality and Social Psychology, 54, 96-107. 